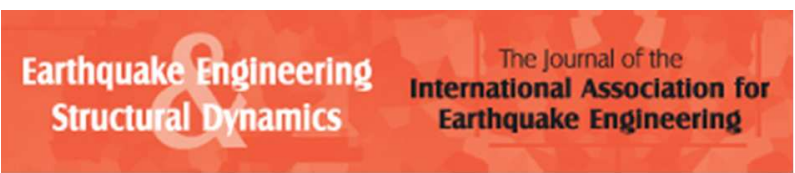

\title{
HYBRID SIMULATIONS OF A MULTI-SPAN RC VIADUCT WITH PLAIN BARS AND SLIDING BEARINGS
}

\begin{tabular}{|c|c|}
\hline Journal: & Earthquake Engineering and Structural Dynamics \\
\hline Manuscript ID: & EQE-14-0283.R1 \\
\hline Wiley - Manuscript type: & Research Article \\
\hline Date Submitted by the Author: & 13-Feb-2015 \\
\hline Complete List of Authors: & $\begin{array}{l}\text { Abbiati, Giuseppe; University of Trento, Department of Civil, Environmental } \\
\text { and Mechanical Engineering } \\
\text { Bursi, Oreste S.; University of Trento, Department of Civil, Environmental } \\
\text { and Mechanical Engineering } \\
\text { Caperan, Philippe; European Commission, Joint Research Centre (JRC), } \\
\text { Institute for the Protection and Security of the Citizen, European } \\
\text { Laboratory for Structural Assessment Unit } \\
\text { DiSarno, Luigi; University of Sannio, Department of Engineering } \\
\text { Molina, Francisco; European Commission, Joint Research Centre (JRC), } \\
\text { Institute for the Protection and Security of the Citizen, European } \\
\text { Laboratory for Structural Assessment Unit } \\
\text { Paolacci, Fabrizio; University Roma Tre, Department of Engineering } \\
\text { Pegon, Pierre; European Commission, Joint Research Centre (JRC), } \\
\text { Institute for the Protection and Security of the Citizen, European } \\
\text { Laboratory for Structural Assessment Unit }\end{array}$ \\
\hline Keywords: & $\begin{array}{l}\text { Seismic assessment, Thirteen-bay bridge, Concave sliding bearing, Hybrid } \\
\text { Simulation }\end{array}$ \\
\hline
\end{tabular}




\title{
HYBRID SIMULATION OF A MULTI-SPAN RC VIADUCT WITH PLAIN BARS AND SLIDING BEARINGS
}

\author{
Abbiati G. ${ }^{1}$, Bursi O.S. ${ }^{1}$, Caperan P. ${ }^{2}$, Di Sarno L. ${ }^{3}$, Molina F.J. ${ }^{2}$, Paolacci $F^{4}{ }^{4}$, Pegon P. ${ }^{2}$ \\ ${ }^{1}$ University of Trento, Department of Civil, Environmental and Mechanical Engineering, Via \\ Mesiano 77, 38123 Trento, Italy \\ ${ }^{2}$ European Commission, Joint Research Centre (JRC), Institute for the Protection and Security \\ of the Citizen, European Laboratory for Structural Assessment Unit, Via Enrico Fermi 2749, \\ 21027 Ispra (VA), Italy \\ ${ }^{3}$ University of Sannio, Department of Engineering, Piazza Roma 21, 82100 Benevento, Italy \\ ${ }^{4}$ University Roma Tre, Department of Engineering, Via Vito Volterra 62, 00146 Rome, Italy
}

Summary: This paper deals with the seismic response assessment of an old reinforced concrete (RC) viaduct and the effectiveness of friction-based retrofitting systems. Emphasis was laid on an old bridge, not properly designed to resist seismic action, consisting of twelve portal piers which support a thirteen-span bay deck for each independent roadway. On the basis of an OpenSEES Finite Element (FE) frame pier model, calibrated in a previous experimental campaign with cyclic displacement on three 1:4 scale frame piers, a more complex experimental activity using hybrid simulation (HS) has been devised. The aim of simulation was twofold: i) to increase knowledge of non-linear behavior of RC frame piers with plain steel rebars and detailing dating from the late 1950s; ii) to study the effectiveness of sliding bearings for seismic response mitigation. Hence, in order to explore the performance of the as built bridge layout and also of the viaduct retrofitted with friction-based devices, at both serviceability and ultimate limit state conditions, HS tests were carried out. In particular, two frame piers were experimentally controlled with 8-actuator channels in the as built case while two frame piers and eight sliding bearings were controlled with 18 -actuator channels in the isolated case. The remaining frame piers were part of numerical substructures and were updated offline to accurately track damage evolution.

KEYWORDS: Seismic assessment, Thirteen-bay bridge, Concave sliding bearing, Hybrid Simulation.

\section{INTRODUCTION}

\subsection{Background and motivation}

The seismic vulnerability assessment of existing and new lifeline systems, especially transport systems, is of paramount importance in resilient social communities. Bridge systems and highways are primary elements that can be used for rescue operations in the aftermath of moderate-to-major earthquakes. Most of today's existing transport systems in Europe were built in the late $60 \mathrm{~s}$ and early $70 \mathrm{~s}$ and were designed primarily for gravity loads. As a result, such systems do not employ seismic detailing and hence their structural performance is inadequate under severe earthquake ground motion. The state of the art in Italy is summarized in [1].

In the US, to investigate a number of topics related to seismic assessment and retrofitting bridges, several research programs were funded by the Federal Highway Administration (FHWA) and standards have been issued [2, 3]. Conversely in Europe, while Part 3 of Eurocode 8 addresses the assessment and retrofitting of existing 
buildings [4], no part of Eurocode 8 covering existing bridges is available. However, research is very active in this respect [5].

The assessment of seismic vulnerability in existing bridges is a complex process. Much information on many factors is missing; geometrical and mechanical properties, structural modifications applied during bridge life, reliable estimate of gravity loads etc. Moreover, the reliability of seismic assessment is low, due to lack of knowledge of the mechanisms that characterize inelastic structural response. As a result, the effective use of advanced methods and processing tools is often impossible or unreliable. For example, steel reinforcement in old RC bridges consists mainly of smooth steel bars. Thus, to investigate the influence of their bond-slip and anchorage efficiency on the member response, existing formulations have been updated [6]; and specific experimental/numerical investigations were conducted on portal frame piers in an old reinforced concrete viaduct $[7,8]$.

Existing old bridges can be rehabilitated also by means of passive control. Thus, seismic isolation/dissipation can represent an effective alternative to reduce the dynamic response of bridges designed for vertical loads only. Passive control is frequent today; nonetheless, its applicability and effectiveness on old bridges has only been investigated marginally. In addition, further comparative analyses are needed to better understand the relative performance of differing isolation systems $[9,10]$.

The dynamic response of bridges subject to earthquake loading can be reproduced by means of HS, where bridge decks having well established mechanical properties are simulated by numerical substructures (NS), while piers or bearings without reliable numerical models are tested using physical substructures (PS). Coupling forces between PS and NS are measured, analyzed and instantly applied to NS in every time step of the process. The HS technique has been improved and modified for large bridge testing. Advanced control methods have been developed to compensate for both load relaxation and signal/noise ratio and for control and measurement error [11, 12]. Non-iterative monolithic and partitioned time integration algorithms have been devised and applied to deal with increased DoFs or nonlinear NS [13-15]. Moreover, MR dampers have been tested with HS and adoption of the convolution integral method applied to decks [16], without considering any stability issue of the coupled system; and software platforms and communication protocols have been implemented for multi-pier bridge HS [17]. However, HS with nonlinear NS is very challenging and requires advanced numerical techniques [18-20]. In particular, Yang et al. [18] proposed online updating of multiple identical bridge piers in NS based on experimental data from identical piers of PS. Nonetheless, the study was numerical only, and when nonlinear NS and PS piers differ both geometrically and mechanically, HS clearly becomes more demanding.

\subsection{Scope}

Though the above research advanced the testing and assessment of multi-pier bridges, there are still issues related to: i) in depth understanding of old RC bridge behavior when not designed to resist seismic action; ii) the presence of plain steel bars for which few studies have been carried out; iii) the effectiveness of isolation retrofit systems. These issues were explored by the RETRO project [21] and the main findings [22] are reported below.

In particular, to examine the response of a typical old viaduct in its out-of-plane direction, a stepped approach is presented below. Starting from a previous experimental campaign [7] consisting of cyclically imposed displacements on the in-plane response of three 1:4 reduced scale models of a RC portal frame pier: 1) an OpenSEES frame pier model was calibrated; 2) a 2-level and a 3-level one-bay RC frame pier specimens 1:2.5 scale-, were constructed; 3 ) the two frame piers were tested both at serviceability 
and ultimate limit state conditions, using HS in order to include the remaining 10 frame piers and the entire deck; 4) HS tests were also conducted on the same viaduct retrofitted by means of single Concave Sliding Bearings (CSBs). In this particular case, both physical and numerical frame piers were considered together with physical and numerical CSBs. In several HS tests nonlinear phenomena occurred, so both numerical piers and CSBs were updated offline to accurately track damage evolution.

\section{THE RIO TORTO VIADUCT CASE STUDY}

\subsection{Viaduct description}

The Rio Torto viaduct is an RC structure built during the 1960s between Florence and Bologna in Italy. Twelve portal piers support the thirteen-span decks of two independent roads as shown in Figures 1 and 2. End spans measure $29 \mathrm{~m}$, while internal spans are $33 \mathrm{~m}$. There are six Gerber saddles at the middle of the bridge and close to both abutments as shown in Figure 2(a). Additional details can be found in [7].
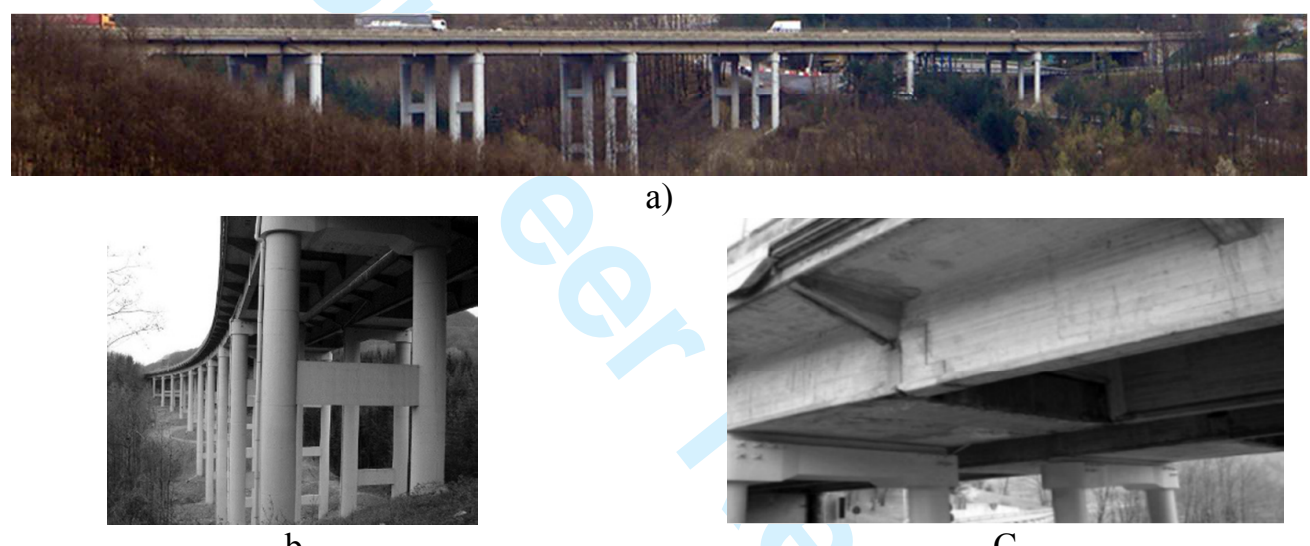

a)

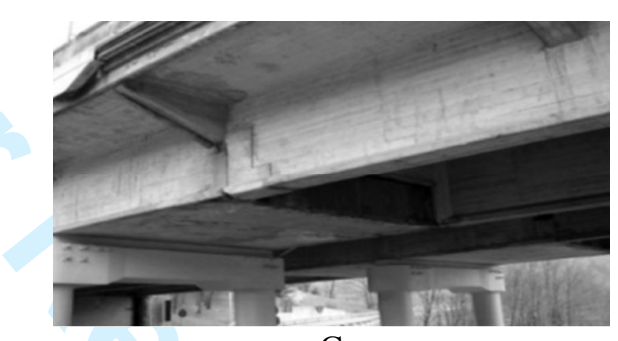

$\mathrm{C}$

Figure 1. a) Lateral view of the Rio Torto viaduct; b) detail of frame piers; and c) close-up view of a Gerber saddle.

Solid and hollow circular cross section columns characterize short and tall piers, respectively, as depicted in Figure 2(a). The diameters are $1200 \mathrm{~mm}$ and $1600 \mathrm{~mm}$. For the sake of completeness, Table 1 summarizes the heights of all piers.

Table 1. Heights of piers of the Rio Torto Bridge.

\begin{tabular}{cccccc}
\hline Pier & Height $[\mathbf{m}]$ & Pier & Height $[\mathbf{m}]$ & Pier & Height $[\mathbf{m}]$ \\
\hline 1 & 17.35 & 5 & 27.86 & 9 & 25.74 \\
\hline 2 & 30.61 & 6 & 39.41 & 10 & 17.19 \\
\hline 3 & 30.49 & 7 & 41.34 & 11 & 14.37 \\
\hline 4 & 26.75 & 8 & 36.49 & 12 & 13.80 \\
\hline
\end{tabular}

A cap beam and single or multiple transverse beams of rectangular cross section connect each column pair at the top and at intermediate levels, respectively. In particular, Figure 2(b) depicts part of a frame pier and the deck cross section. Moreover, two steel dowels connect each pier to the deck, which is simply supported at the abutments. 


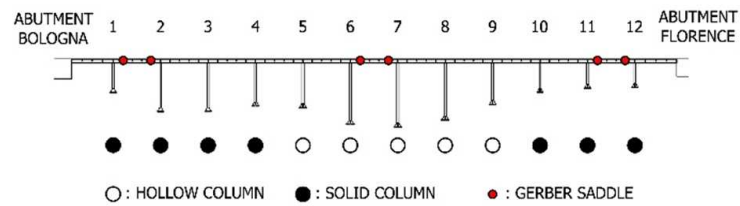

a

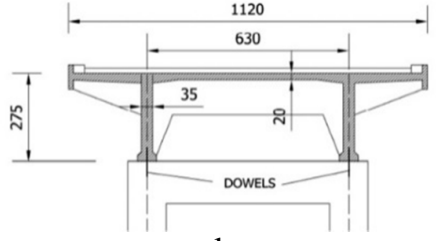

b

Figure 2. a) Structural scheme of the Rio Torto Bridge; b) Cross section of the deck.

Each pier foundation consists of a large RC plinth resting on bedrock; hence, soilstructure interaction can be neglected. The uniformly distributed weight of the deck is approximately $170 \mathrm{kN} / \mathrm{m}$ for each roadway. Thus, each pier bears a vertical load of between $5300 \mathrm{kN}$ and $5600 \mathrm{kN}$. These values are much larger than the axial load decrement, about $2700 \mathrm{kN}$, owing to overturning effects. So, any foundation uplift is excluded.

On the basis of a previous experimental campaign and simulations presented in $[7,8]$, OpenSEES-based [23] numerical simulation of the seismic response of the bridge in the as-built configuration proved that the most likely damage patterns at the ultimate limit state correspond to brittle failure of transverse beams and fixed-end rotation at beam-tocolumn and base-column joints. Therefore, the installation of pairs of CSB isolation devices between each pier and the deck was proposed for seismic retrofitting, together with the removal of the Gerber saddles. Figure 3 depicts the relevant layout, the schematic of a single CSB and typical hysteretic loops.

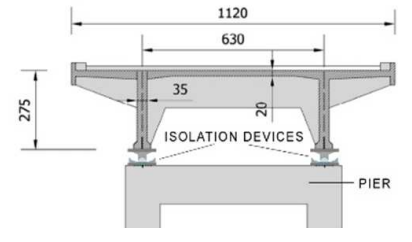

a

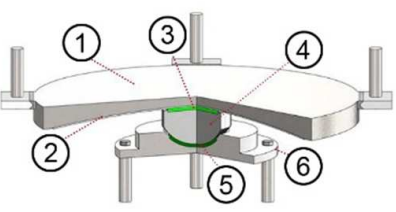

b

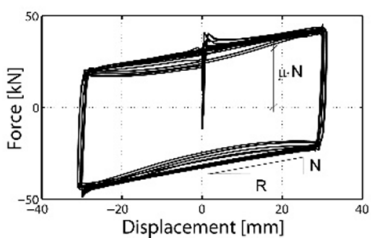

$\mathrm{c}$

Figure 3. a) Location of CSBs isolation devices on a generic frame pier; b) sketch of a single device; c) typical hysteretic loop in simple shear.

The following force-displacement relationship describes the shear response of the device:

$V=\mu_{f} \operatorname{sign}(\dot{x}) \cdot N+\frac{N}{R} x$

where $\mu_{f}$ is the friction coefficient, $N$ is the normal force, $R$ is the device curvature radius and $x$ and $\dot{x}$ are the horizontal sliding displacement and velocity of the isolator, respectively. As can be seen in Figure 3(c), the resulting hysteretic loops are characterized by sharp edges owing to the stick-slip behavior of the device. The design of the selected CSB devices relied on the displacement-based approach and relevant details can be found in [24].

\subsection{Selection of input ground motions}

The input ground motions adopted for viaduct modeling and HS are natural accelerograms representative of the seismic zone -the Emilia Romagna region- where the viaduct is located. Given the recent earthquake swarms in the area -especially the earthquake records of 20 and 29 May 2012-, these seismic records were employed [25]. The Italian seismic standards are based on seismic hazard assessment [26]; therefore, on 
the basis of soil conditions B and considering the nominal life equal to 100 years with class of construction equal to IV, doubling the nominal life, the maximum PGA would correspond to $1.71 \mathrm{~m} / \mathrm{s}^{2}$ for Damage Limit conditions, $3.02 \mathrm{~m} / \mathrm{s}^{2}$ for Life Safety and $3.45 \mathrm{~m} / \mathrm{s}^{2}$ for Collapse Prevention. Only two limit states were considered for the seismic performance assessment of the as built Rio Torto Bridge: the Damage Limit condition corresponding to the Serviceability Limit State (SLS) and the Life Safety corresponding to the Ultimate Limit State (ULS), respectively. Despite PGAs of these limit states were very close, the Mirandola accelerograms were utilized because response spectra and durations of both accelerograms matched the outcomes of the Italian standards. Thus, the accelerogram of May 29th East-West was used for the SLS with $2.56 \mathrm{~m} / \mathrm{s}^{2}$ PGA while the North-South component accelerogram with $2.67 \mathrm{~m} / \mathrm{s}^{2}$ PGA was adopted for the ULS. Spectra and accelerograms of the aforementioned Mirandola North-South component are shown in Figure 4.
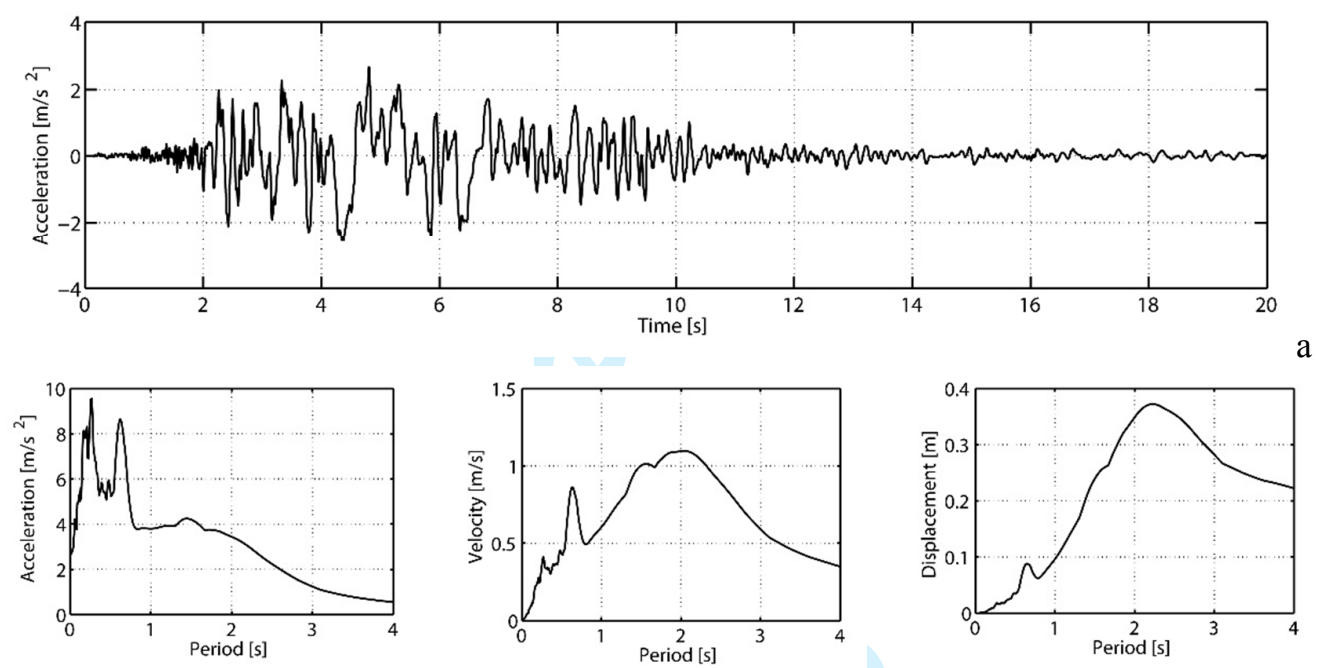

Figure 4. (a) Accelerogram used in numerical and hybrid simulation; (b) Response spectra of the Mirandola North-South component record of 29 May 2012: acceleration (left), velocity (middle) and displacement (right) spectrum.

A 5\% viscous damping was assumed. For SLS conditions the maximum spectral acceleration corresponding to the fundamental period $\mathrm{T}=1.6 \mathrm{~s}$ of the bridge is about 2 $\mathrm{m} / \mathrm{s}^{2}$. Other details can be found in [21].

\section{SUBSTRUCTURING AND REDUCED MODELS OF THE RIO TORTO VIADUCT}

\subsection{Reference finite element models}

In order to implement HS, refined finite element (FE) models of a single lane of the bridge were implemented in the OpenSEES environment [23]. Linear beam elements were selected to model the deck; Gerber saddles were inserted as cylindrical hinges, which allowed for yaw -rotation around the $\mathrm{Z}$ axis of Fig. 5(a)- and pitch -rotation around the $\mathrm{X}$ axis- relative rotation between deck elements. Translational DoFs of both abutments were fixed while rotation released. These assumptions were supported by numerical simulation. Rigid links connected the deck to piers, which were assumed as clamped at the base. As a result, the offset distance between the center of gravity of the deck cross section and the cap beam level of piers was considered. Figure 5 depicts both the deck-to-pier connection modeling and a FE model of Pier \#12. 


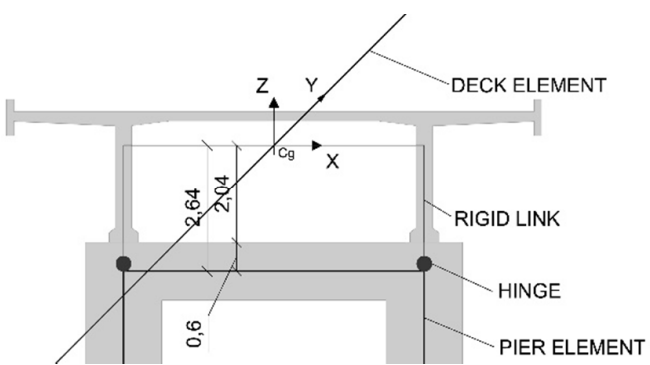

A
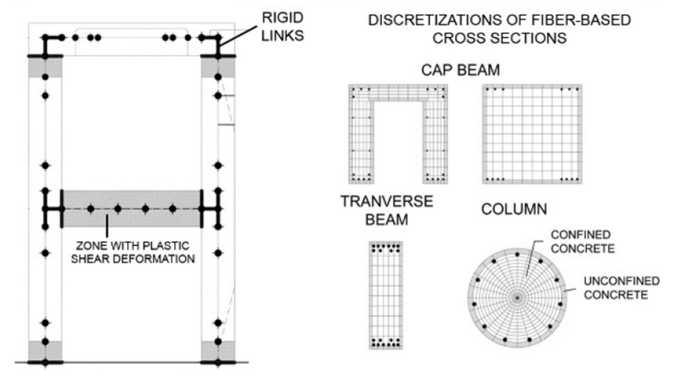

b

Figure 5 a) Details of the FE model of a pier-deck connection; b) schematic view of the OpenSEES fiber-based FE model of Pier \#12. Dimensions in meters.

As can be appreciated from Figure 5(b), nonlinear fiber-based beam elements allowed for accurate discretization of cross sections as well as for positions and dimensions of plain rebars. The contribution of the concrete tensile strength was neglected in view of the use of plain steel bars and poor seismic detailing. In fact, Marefat et al. [27] showed that cracks can be observed even for small values of stress; this phenomenon implies little contribution to stiffness by the initial concrete tensile strength. Therefore, the Concrete01 material of OpenSEES, was employed to simulate concrete behavior. In detail, we assumed: the maximum concrete strength $\mathrm{f}_{\mathrm{pc}}=26 \mathrm{MPa}$ with a corresponding deformation $\varepsilon_{\mathrm{psc} 0}=0.25 \%$; the asymptotic concrete strength $\mathrm{f}_{\mathrm{pcu}}=22 \mathrm{MPa}$ with a relevant deformation $\varepsilon_{\mathrm{psc}}=0.6 \%$. Rebars were represented by the Steel02 material with $\mathrm{f}_{\mathrm{y}}=360$ $\mathrm{MPa}$, along with $\mathrm{E}=205000 \mathrm{MPa}$ and $\mathrm{E}_{\mathrm{p}} / \mathrm{E}=0.025$. Because shear behavior plays a fundamental role in characterizing the nonlinear response of existing structures that lack seismic reinforcement detailing, a phenomenological shear-strain hysteretic relationship was assumed to model the nonlinear shear behavior of the transverse beams. This was based on a tri-linear envelope curve embedding both stiffness and strength degradation and pinching [28]; shear deformations were defined in previous cyclic tests on the 1/4 scale mock-up specimen of Pier \#12 [7]. The OpenSEES section aggregator command joined the hysteretic shear and flexural behavior, though their interaction was neglected. For the retrofit case, i.e. the isolated case of Figure 3a, a pair of single surface friction pendulum bearing OpenSEES elements were inserted between each frame pier and the related rigid link elements of the deck in Figure 5a. Consistently, the Gerber saddles of Figure 2a were removed. As a result, OpenSEES reference models (OpenSEES RM) for both the as built and the isolated cases were assembled.

\subsection{Reduced models of piers, isolators and viaduct}

To comply with the computational, physical and control requirements of the experimental facility for complex emulated systems, some of which will be discussed in Subsection 4.2, a reduced model of the viaduct was deemed necessary. Therefore, 88DoFs substructure reduced models for the out-of-plane response of the viaduct were assembled for both the as built and the isolated cases [29]. Figure 6 depicts both bridge configurations with node numbering and dimensions. In detail, the deck was characterized by cross sectional characteristics $A=4.63 \mathrm{~m}^{2}, \mathrm{I}_{\mathrm{xx}}=51.90 \mathrm{~m}^{4}, \mathrm{I}_{\mathrm{zz}}=3.45 \mathrm{~m}^{4}$ and $\mathrm{I}_{\mathrm{yy}}=0.10 \mathrm{~m}^{4}$. Additional transversal stiffness was provided by nonlinear reduced S-DoF piers of Fig. 6(a), or linear reduced S-DoF piers and nonlinear CSBs of Fig. 6(b). 
Figure 6. Plan view of the reduced nonlinear models of the Rio Torto viaduct in: a) as built configuration; b) isolated configuration. Dimensions in $\mathrm{m}$.

To estimate the quality of reduction techniques, comprehensive time history analyses of the OpenSEES RMs were carried out at both the SLS and ULS. With reference to the as built configuration, all piers showed hysteretic dissipation already at SLS. Conversely, time history analyses conducted in the isolated case proved that isolator pairs dissipated the most hysteretic energy while piers remained in the linear range. As a result, relevant models depicted in Figure $6 \mathrm{a}$ and $6 \mathrm{~b}$ significantly differ; conversely, a linear response of the deck was observed for both conditions. Moreover, numerical simulation highlighted that frame piers moved in the viaduct out of plane. Therefore, the internal constraint setting was simplified and out-of-plane displacements of piers were fixed, while relative rotation between deck and piers was released. Accordingly, nonlinear SDoF reduced models of piers and CSBs were devised. These assumptions were supported by numerical simulation.

Dynamic simulation of the viaduct proved that higher modes of frame piers were not excited during seismic loading and that they experienced static in-plane deformation. Therefore, the so-called Guyan static condensation [30] was applied to retain a S-DoF and to reduce both their stiffness and mass matrices. In order to extend the proposed reduced S-DoF frame pier model to the nonlinear range, springs governed by the wellknown Bouc-Wen model replaced their elastic stiffness. This model was chosen because, differently from other piecewise linear models involving several rules and parameters, it offers a compact and continuous representation of hysteresis with the few parameters described here. In particular, to replicate the softening behavior of OpenSEES-based frame piers, which was inherited from material constitutive laws, the factor $1 /\left(1+\alpha x^{2}\right)$ was added to modify the linear component of the tangent stiffness. Moreover, to simulate the average degradation of each pier, a $\rho$ parameter was introduced to modulate the linear stiffness $k$ [31]. The resulting formulation reads:

$$
\left\{\begin{array}{l}
r+c \cdot \dot{x}+m \cdot \ddot{x}=-f \cdot \ddot{u}_{g}(t)+p(t) \\
\dot{r}=\left[\rho \cdot k /\left(1+\alpha \cdot x^{2}\right)-(\beta \cdot \operatorname{sgn}(\dot{x} \cdot r)+\gamma)|r|^{n}\right] \cdot \dot{x}
\end{array}\right.
$$

where $\beta, \gamma$ and $n$ are parameters of the Bouc-Wen model. For the purpose of identifying $\rho, \beta$ and $\alpha$, each substructure pier was considered as a stand-alone Single-Input-SingleOutput (SISO) system, while to decrease the computational burden of consequent optimization problems, $\gamma$ and $n$ were set to zero and to one, respectively [32]. Because reduced nonlinear springs were not capable of reproducing pier behavior at their full 
operating range, a set of parameters was identified for each different limit state. Identified values can be found in [22]. Figure 7 depicts comparisons between displacement responses of OpenSEES RMs and reduced models of Piers \#9 and \#11 at ULS. The agreement is favorable.

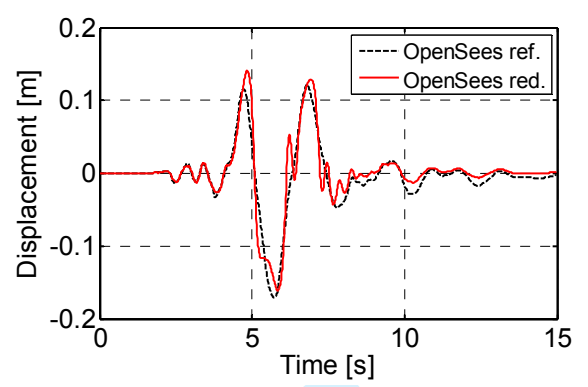

a

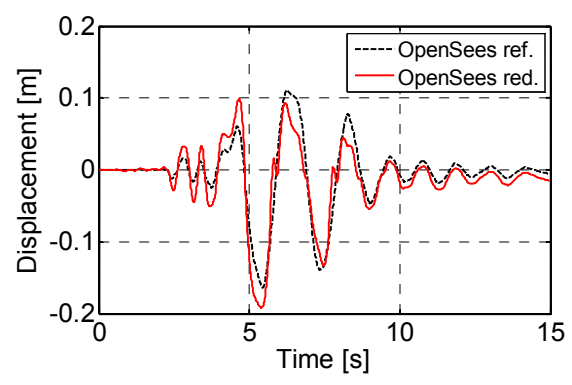

$\mathrm{b}$

Figure 7. Comparisons of displacement responses of reference and reduced piers al ULS: a) Pier \#9; and b) Pier \#11.

With regard to the isolated case, $\beta$ and $\rho$ were set to zero and one for all frame piers, respectively; thus, they behaved elastically as assumed in the viaduct model of Figure 6b. Single Concave Friction Pendulum Bearing OpenSEES elements embed a physical model that can replicate the slip mechanism of CSB devices. Because bilinear shapes characterize inherent hysteretic loops, the state space model proposed by Mostaghel [33] was selected to reproduce the NS of isolator elements. Figure 8 shows both the relevant S-DoF oscillator and its characteristic hysteretic loop.

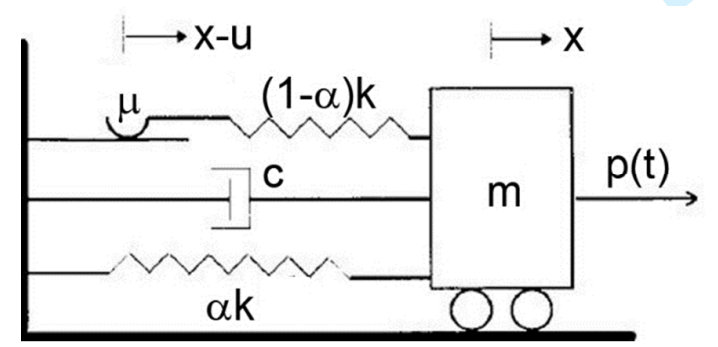

A

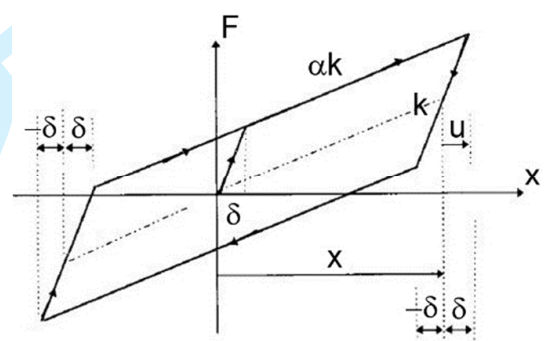

b

Figure 8. a) Hysteretic S-DoF oscillator; b) relevant bilinear hysteretic loop

The corresponding ODE set,

$$
\left\{\begin{array}{l}
\alpha k \cdot x+(1-\alpha) k \cdot u+c \cdot \dot{x}+m \cdot \ddot{x}=p(t) \\
\dot{u}=[\bar{N}(\dot{x}) \bar{M}(u-\delta)+M(\dot{x}) N(u+\delta)] \dot{x}
\end{array}\right.
$$

defines the non-degenerating hysteretic bilinear system of the type depicted in Figure $8 \mathrm{~b}$ under a given load history $p(t)$, where: $k$ is the total stiffness; $\alpha$ defines the stiffness ratio and $\delta$ represents the system yield displacement. The state variable $u$ refers to the slip displacement; the remaining functions $N, M, \bar{N}$ and $\bar{M}$ are defined as 


$$
\left\{\begin{array}{l}
N(w)=0.5(1+\operatorname{sgn}(w))[1+(1-\operatorname{sgn}(w))] \\
M(w)=1-N(w) \\
\bar{N}(w)=M(-w) \\
\bar{M}(w)=N(-w)
\end{array}\right.
$$

To identify $\alpha, k$ and $\delta$, a penalty function was set as a difference norm between restoring forces of the reference and of the reduced isolator elements. Identified values of Eq. (3) read: $\hat{k}=2.03 e 8 \mathrm{~N} / \mathrm{m}, \hat{\alpha}=0.46 e-2$ and $\hat{\delta}=0.05 e-2 \mathrm{~m}$ [22]. Although the effect of variable vertical loads was neglected in the NSs, simplified bilinear hysteretic models well reproduced the response of all OpenSEES isolators. In this respect, Figure 9 compares hysteretic loops of reference elements installed on the right pier columns of Piers \#9 and \#11 at ULS.

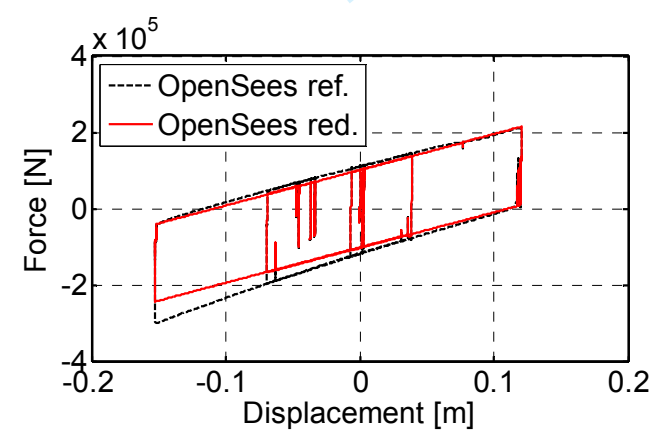

a

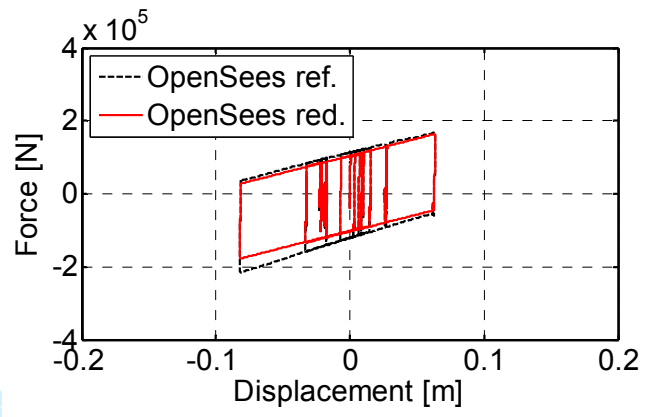

b

Figure 9. Comparisons of hysteretic loops of reference and reduced isolators at ULS installed on the pier right column of: a) Pier \#9; and b) Pier \#11.

The same matching quality was observed for all devices. As a result, they were implemented as NSs for the purpose of HS of the Rio Torto viaduct in the isolated configuration. The normalized root mean square error (NRMSE) defined here:

$\operatorname{NRMSE}\left(\mathbf{x}_{r e d}, \mathbf{x}_{r e f}\right)=\frac{\sqrt{\frac{1}{m} \sum_{i=1}^{m}\left(x_{i, r e d}-x_{i, r e f}\right)^{2}}}{\max \left(\mathbf{x}_{r e f}\right)-\min \left(\mathbf{x}_{r e f}\right)}$

where subscript red stands for reduced and subscript ref for reference, was employed to prove the effectiveness of tailored reduced models in reproducing OpenSEES RMs of the viaduct. In greater detail, NRMSE values were computed for transversal displacement responses of piers measured at the cap beam level and relative displacement histories of isolators. Average values were 0.06 and 0.045 for piers and CSBs, respectively [32]. These values corroborated the effectiveness of the assembled reduced models of Figure 6, which were successfully implemented as NSs.

\section{HYBRID SIMULATION FRAMEWORK FOR THE RIO TORTO VIADUCT}

In order to shed light on the issues stated in Subsection 1.2, a comprehensive set of HS of the viaduct was conceived. In detail for the as built configuration, Piers \#9 and \#11 were experimentally substructured. They represented the shortest of the solid and 
hollow section columns, respectively; moreover, they were significantly stressed piers, as suggested by numerical simulations [22]. The same specimens together with related pairs of CSB devices were tested for the isolated case at the ELSA Lab. of JRC in Ispra, Italy.

\subsection{Experimental set-ups and sensor layout}

Due to size and capacity of the experimental facility, 1:2.5 scale mock-up models of Piers \#9 and \#11 were considered. Since gravity loads did not play an important role in piers, Procedure \#2 proposed by Kumar et al. [34] was selected for specimen scaling. Therefore, scale factors $\mathrm{S}, \mathrm{S}^{2}$ and 1 were applied to displacements, forces and time, respectively. Hence, both stress and strain quantities were preserved. Figure 10 depicts both frame piers and CSBs.

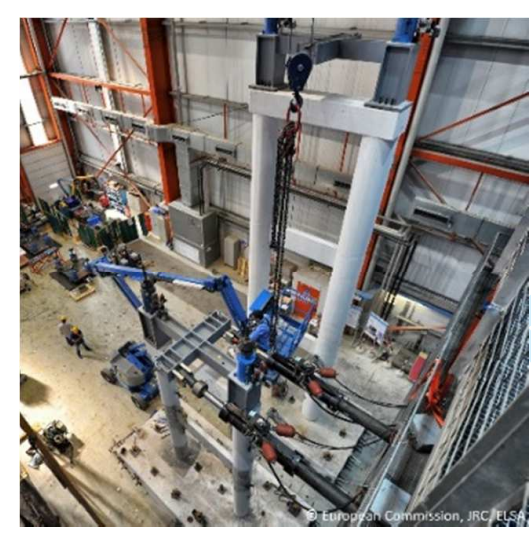

a

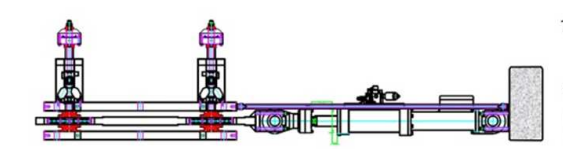

c)

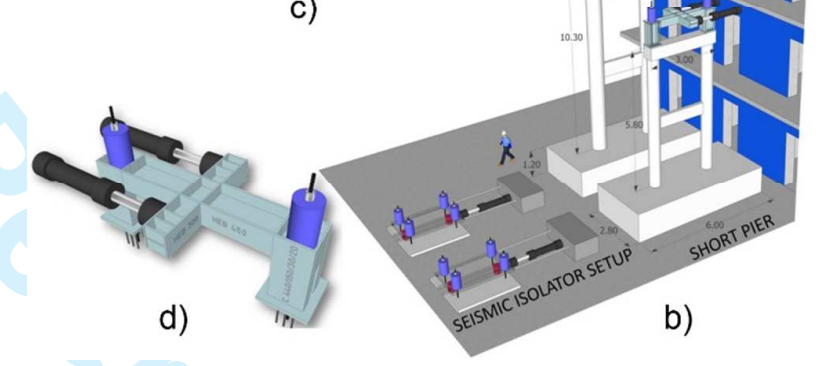

$\mathrm{b}, \mathrm{c}, \mathrm{d}$

Figure 10. 1:2.5 mock-up scale specimens of Piers \#9 and \#11; b) view of the test set-up; c) CSBs set-up; d) horizontal and vertical loading system of frame piers.

According to Figure 10a, the taller Pier \#9 was characterized by 3 levels and a total height of $11.50 \mathrm{~m}$, while the shorter Pier \#11 was characterized by 2 levels and $7.00 \mathrm{~m}$ of total height. Both specimens were provided with a $6.00 \mathrm{~m} \times 2.80 \mathrm{~m} \times 1.20 \mathrm{~m}$ block foundation. Plain steel bars of diameters 8 and $10 \mathrm{~mm}$ replaced full-scale diameters of 20 and $24 \mathrm{~mm}$, respectively. Therefore, a small approximation occurred for the $24 \mathrm{~mm}$ diameter. Further details of frame pier specimens can be found in [21]. Mock-up scale 1:2.5 model of CSBs were manufactured by $\mathrm{ALGA}^{\mathrm{TM}}$. The foreseen full-scale radius of the concave sliding surface was reduced from 3000 to $1200 \mathrm{~mm}$, while the same friction coefficient $\mu_{f}=4 \%$ was considered.

To perform HS, a maximum of eighteen hydraulic actuators was employed at the ELSA facility for the isolated case. In agreement with the assumptions of Subsection 3.2, vertical DoFs were removed from NSs. Nonetheless, corresponding gravity loads were crucial for a realistic simulation of physical frame piers and CSBs. Therefore, they were applied to all specimens by means of force controlled actuators according to nominal values implemented in OpenSEES RMs. According to Figure 10b, horizontal and vertical actuators were connected to each cap beam by means of rigid steel frames as shown in Figure 10d. They were fitted with vertical lever arms of $0.8 \mathrm{~m}$, see Figure 11a, to allow for the vertical offset between the centre of gravity of the deck cross section and the top of the cap beam of each pier specimen. Vertical gravity loads were applied to each pier through a pair of $500 \mathrm{kN}$ capacity vertical jacks. Conversely, a pair of 500 $\mathrm{kN}$ capacity actuators with stroke $\pm 0.5 \mathrm{~m}$ imposed the horizontal in-plane displacement on each pier. 


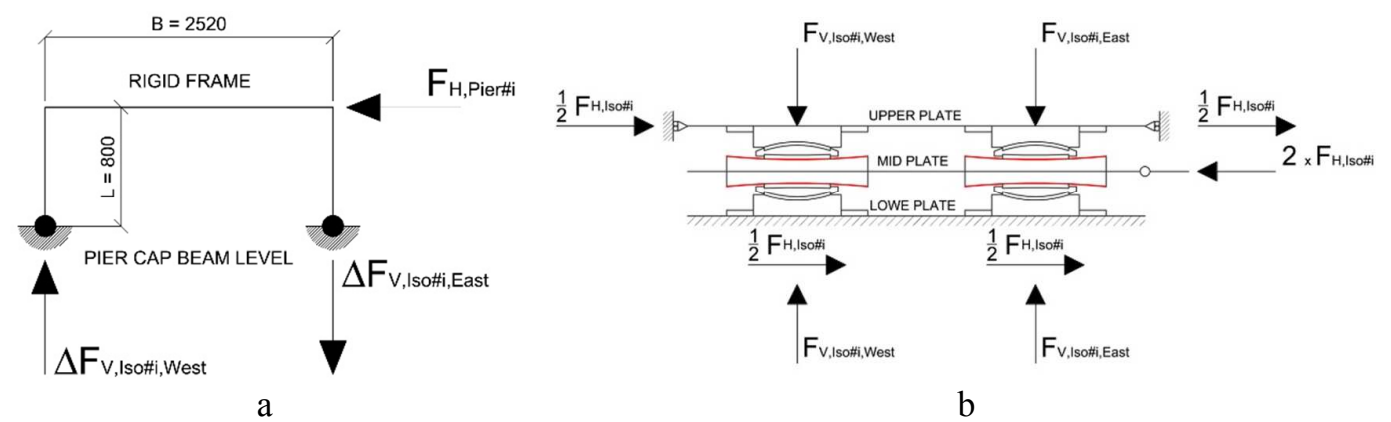

Figure 11. Structural schemes and relevant applied loads for: a) the rigid steel frame of each frame pier; b) the experimental set-up of a CSB isolator group.

As can be appreciated from Figure 11a, the overturning moments due to the lever arms of horizontal actuators applied to piers, induced variations in the vertical pier reactions. With regard to CSBs, Figure $10 \mathrm{~b}$ and $10 \mathrm{c}$ are views of the foreseen experimental set-up, where four jacks applied vertical loads, and a long actuator applied horizontal displacement. Figure $11 \mathrm{~b}$ depicts the relevant structural scheme. In order to cancel spurious friction forces on the CSB restoring force $\mathrm{F}_{\mathrm{H} \text {,iso }}$, four CSBs were employed for each frame pier; therefore to represent the actual situation of two CSBs per frame pier, the horizontal restoring force was halved.

In order to estimate average curvature, shear and axial deformation of element cross sections, a total of 3 and 2 wires - one per level - plus 73 and 48 LVDT displacement transducers were installed on Pier $\# 9$ and $\# 11$, respectively. Additional stereophotogrammetry acquisition was done for Pier \#11 only. Figure 12 provides an overview of the measurement set-up conceived for the shorter Pier \#11.

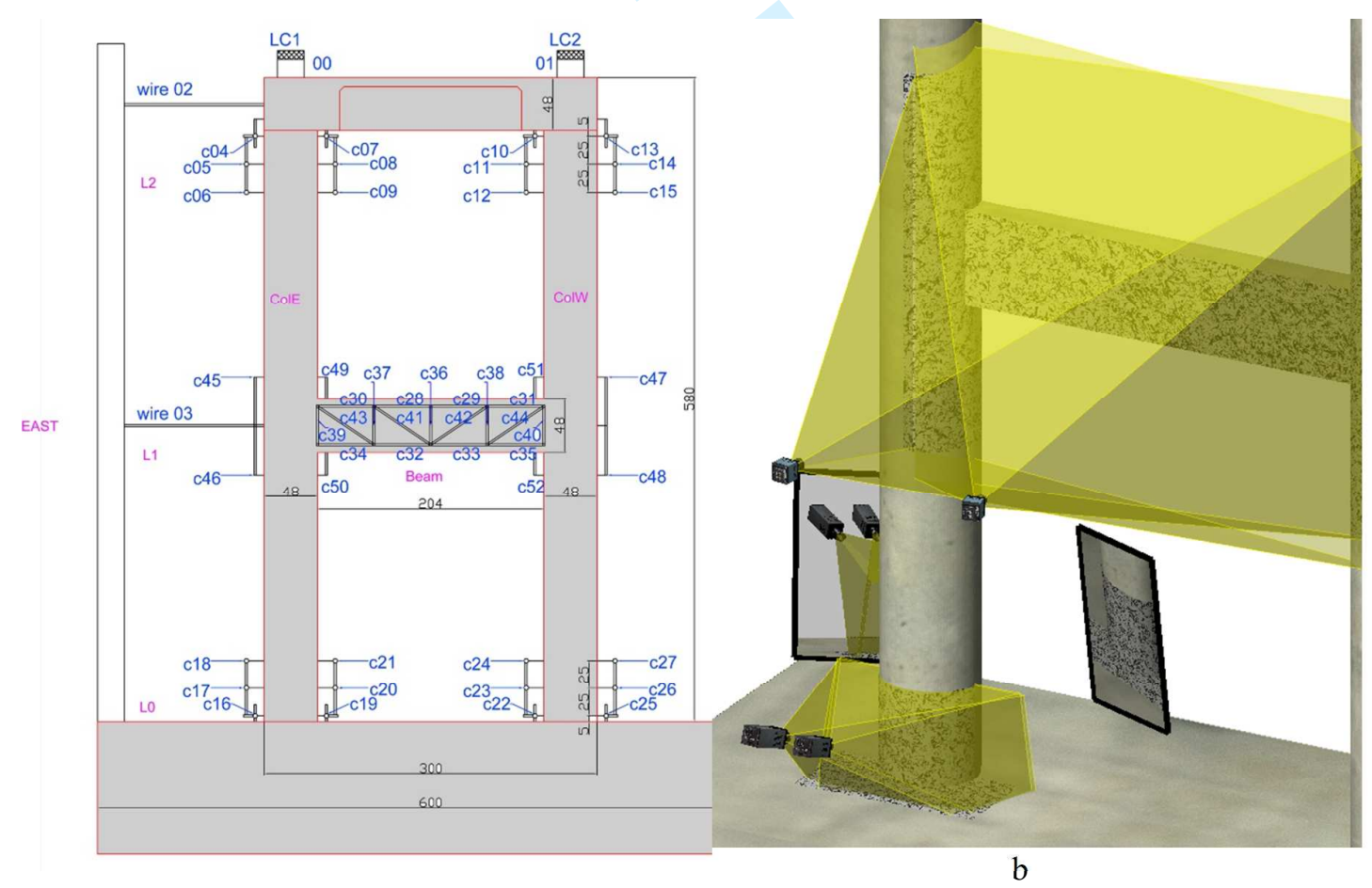




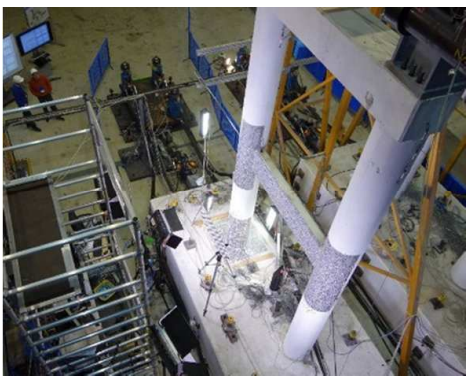

a

$c$

Figure 12. Measurement set-up for Pier \#11: a) layout of LVDT lattices; b) schematic view of the stereophotogrammetry acquisition system; c) photograph of the equipped pier.

As seen in Figure 12a, triangular lattices of LVDT transducers were set to capture cross section responses of transverse beams and joints. Wire displacement transducers measured transverse displacement at reference levels. With reference to the stereophotogrammetry set-up of Figure $12 \mathrm{~b}$, two pairs of high-resolution cameras observed a column-base joint and a transverse element where strong nonlinear responses were expected. Image processing algorithms produced external surface displacement and strain fields in synchronization with the input accelerogram. In order to record the rear of the observed base joint without additional cameras, two astronomical mirrors were placed behind the column; see Figure $12 \mathrm{c}$ in this respect.

\subsection{Hybrid simulation framework}

The ELSA laboratory has for almost 20 years been developing time integration techniques for HS. In particular to avoid load relaxation issues and increase signal/noise ratios, the continuous pseudo-dynamic algorithm was devised without hold and ramp periods [11]. In this context, parallel partitioned time integration algorithms played a crucial role $[14,35]$. As depicted in Figure 13, inherent subcycling capabilities permit synchronization of the two separated integration processes that involve both PSs and NSs with a fine $\Delta \mathrm{t}_{\mathrm{B}}$ and a coarse time step $\Delta \mathrm{t}_{\mathrm{A}}$, respectively. Both small displacement increments at the controller rate in the PS stream and smooth actuator trajectories are achieved. In this particular case, an extended time scale factor $\lambda=(s s \Delta t) / \Delta t_{A}=200$ was assumed together with a subcycling parameter $s s$ shown in Figure 13 equal to 250 and a controller sampling time $\Delta \mathrm{t}=2 \mathrm{~ms}$. As result, $\Delta \mathrm{t}_{\mathrm{A}}=2.5 \mathrm{~ms}$ was applied to NSs, while $\Delta \mathrm{t}_{\mathrm{B}}=0.01 \mathrm{~ms}$ was selected for PSs. Thus, actuator displacement commands were generated at the controller rate $1 / \Delta \mathrm{t}=500 \mathrm{~Hz}$ and solving time limitations were relaxed. Lagrange multipliers impose velocity continuity conditions at shared interface DoFs. This approach leads to stable coupling of standard implicit and explicit Newmark time integrators. Moreover, the PSs run in real time while the Numerical and Physical processes, working on different hardware connected through Internet, exchange information by means of a Microsoft Distributed Component Object Model layer storing the needed values and the semaphore logics for exchange validation.

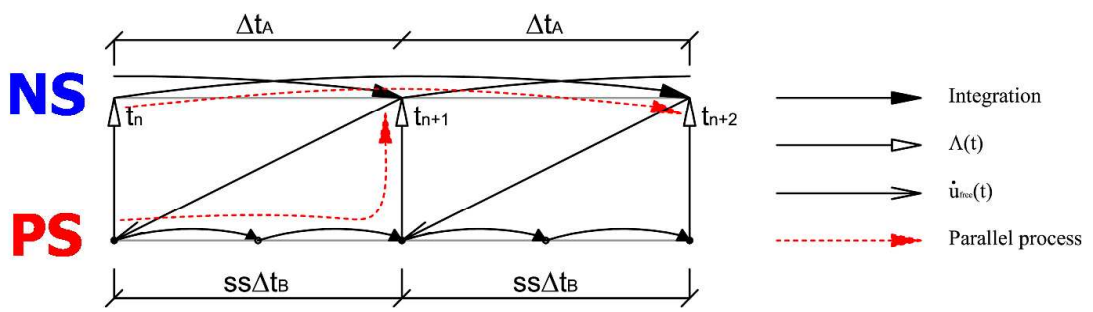

Figure 13. The parallel partitioned algorithm PM with subcycling. 
Up to 18 actuators were controlled at the same time, in the isolated case. In detail, a modular control architecture facilitated the activation/deactivation of each element of the experimental set-up, i.e. frame piers and CSB isolators. Thus, the test program summarized in Table 3 did not require a change to the wiring. To this end, five master computers labeled A to E were set up as slave controllers. These are depicted in Figure 14 as blocks labeled from 1A to 4E. Each one managed the PID control loop of the related hydraulic actuator. Connection schemes are depicted in the same figure.

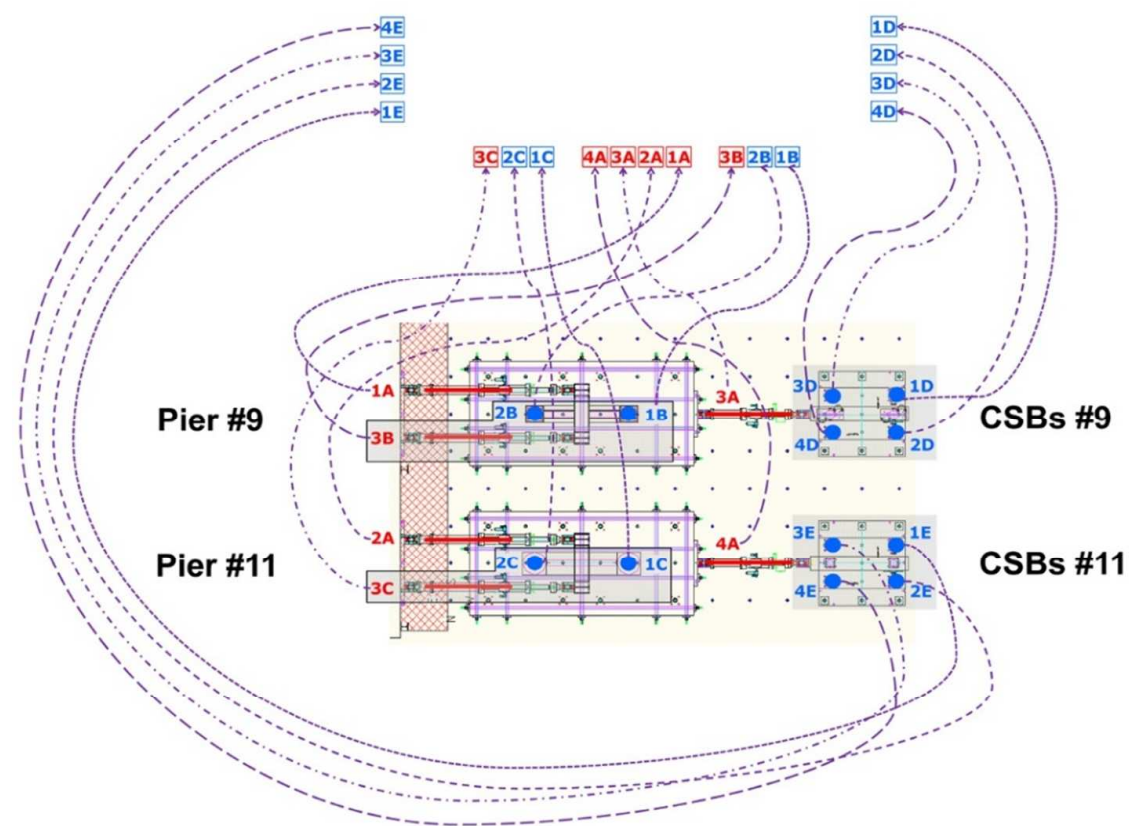

Figure 14. Plan view of the testing set-up with basic cable scheme for force and displacement pilot transducers.

The red blocks refer to six displacement controlled horizontal actuators and the blue to twelve force controlled vertical jacks. Master A drove slave controllers of four horizontal actuators: one per pier and group of isolators. Since horizontal actuator channels only entered into the PM algorithm depicted in Figure 13, Master A ran the partitioned time integrator too. The Distributed Component Object Model (DCOM) architecture facilitated interoperation of both the controller and the computational driver responsible for solution of the NSs. In fact, DCOM allows processes to be distributed efficiently to multiple computers so that both the client and server components of an application can be placed at optimal locations in the network. Masters B and C managed slave controllers of vertical jacks and second horizontal actuators of Pier \#11 and \#9, respectively. Displacement commands delivered by Master A were replicated as tracking signals for this purpose. Masters D and E drove vertical jacks applied to isolators of Pier \#11 and \#9, respectively.

\subsection{Characterization of CSBs}

In order to validate the reduced models of Subsection 3.2, we also needed a preliminary characterization of CSB isolation devices. In particular, the friction parameter $\mu_{f}$ was a main concern. According to Lomiento et al. [36], friction in these devices with a single surface is governed by: i) vertical load, for which $\mu_{f}$ diminishes with increasing load; ii) velocity, $\mu_{f}$ decreasing with velocity; iii) heating, $\mu_{f}$ diminishes with increasing temperature. 
Therefore along the lines of [36], standard testing protocols were conceived, characterized by a series of two displacement sine wave-cycles with variable velocities, amplitudes and vertical loads. Five minute stops were inserted between subsequent patterns to avoid overheating. Experiments were carried out both at the JRC laboratory with the device sketched in Figure $11 \mathrm{~b}$ and at the EUCENTRE in Pavia. Since the scaling Procedure \#2 of Kumar et al. [34] was applied to CSBs samples, the tested velocity range covered that predicted by the OpenSEES software, i.e. about $1000 \mathrm{~m} / \mathrm{s}$. The main test program on scaled devices is listed in Table 2, for which a constant vertical load of $450 \mathrm{kN}$ per CSB device was imposed.

Table 2 Characterization tests on scaled single CSB isolation devices

\begin{tabular}{cccc}
\hline Test \# & Specimen & $\begin{array}{c}\text { Amplitude range } \\
{[\mathbf{m m}]}\end{array}$ & $\begin{array}{c}\text { Peak velocity range } \\
{[\mathbf{m m} / \mathbf{s}]}\end{array}$ \\
\hline 1 & CSB \#9 & 30 (const.) & $0.63-37.7$ \\
\hline 2 & CSB \#9 & $50-10$ & $3.14-0.63$ \\
\hline 3 & CSB \#11 & $50-10$ & $3.14-0.63$ \\
\hline 4 & CSB \#11 & 30 (const.) & $0.63-37.7$ \\
\hline 5 & CSB \#11 & 30 (const.) & 2 (const.) \\
\hline 6 & CSB \#11 & 30 (const.) & 5 (const.) \\
\hline 7 & CSB \#11 & 30 (const.) & 10 (const.) \\
\hline 8 & CSB \#11 & 30 (const.) & 20 (const.) \\
\hline 9 & CSB \#11 & 30 (const.) & 50 (const.) \\
\hline 10 & CSB \#11 & 30 (const.) & 125 (const.) \\
\hline 11 & CSB \#11 & 30 (const.) & 250 (const.) \\
\hline 12 & CSB \#11 & 30 (const.) & 500 (const.) \\
\hline
\end{tabular}

Some relevant results are reported in Figure 15.

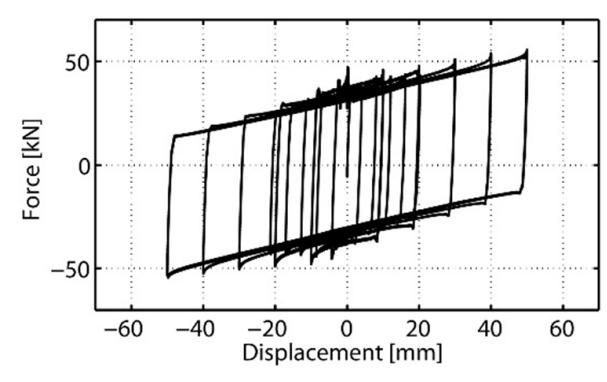

A

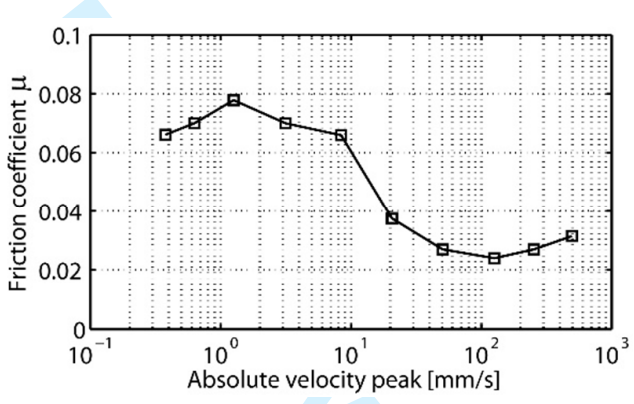

$b$

Figure 15. CSB characteristics of Pier \#11: a) hysteretic response; b) experimental values of $\mu_{f}$ vs velocity peaks at $\lambda=1$.

The $\mu_{f}$ values identified by using the OpenSEES model presented in Subsection 2.1 confirm the trend tracked by Lomiento et al. [36]. In particular $\mu_{f}$ reaches maximum values of about $8 \%$, i.e. almost twice the design value of $4 \%$. As a result, because HS tests were conducted at low velocities, it was decided to reproduce design target $\mathrm{V}$ values of Eq. (1) by reducing vertical force values N. Hence, the consequent reduction of the tangent stiffness of Eq. (1) was numerically compensated. Finally, $\mu_{f}$ was assumed $4 \%$ for all CSBs in NSs.

\subsection{Test program}

With reference to portal pier specimens, preliminary static tests provided initial lateral stiffness. In detail, $1.5 \mathrm{~mm}$ and $2 \mathrm{~mm}$ amplitude cyclic displacements were applied to 
the top of Pier $\# 9$ and $\# 11$, respectively, as shown in Figure 10b. This preliminary characterization task allowed for tuning all PID control loops.

According to the twofold scope stated in Subsection 1.2, the program summarized in Table 3 encompasses HS of the viaduct in both the as built and isolated configurations. In detail, Test k06 was to simulate the linear response of the as built viaduct. To this end, the SLS accelerogram was applied with a PGA reduced to $10 \%$ of its original value. To reproduce the actual damage state of the bridge, Test $\mathrm{k} 07$ simulated the response to the SLS accelerogram in the as built configuration. Induced slight damage including hairline cracks on transverse beams and at column ends. Then, the effectiveness of the proposed retrofit strategy was considered.

Table 3. Nomenclature and characteristics of HS.

\begin{tabular}{|c|c|c|c|c|}
\hline Label & Configuration & Physical Substructures & $\begin{array}{l}\text { Accelerogram and PGA } \\
\text { scaling }\end{array}$ & Date \\
\hline k06 & as built & Piers \#9 and \#11 & SLS, $10 \%$ & $08 / 11 / 2013$ \\
\hline \multicolumn{5}{|c|}{ Updating of the OpenSEES RM and NSs } \\
\hline k07 & as built & Piers \#9 and \#11 & SLS, $100 \%$ & $08 / 11 / 2013$ \\
\hline \multicolumn{5}{|c|}{ Updating of the OpenSEES RM and NSs } \\
\hline 101 & isolated & Piers \#9 and \#11 & SLS, $100 \%$ & $12 / 11 / 2013$ \\
\hline 102 & isolated & Piers \#9 and \#11 & ULS, $100 \%$ & $13 / 11 / 2013$ \\
\hline n01 & isolated & CSBs \#9 and \#11 & SLS, $100 \%$ & $14 / 11 / 2013$ \\
\hline p01 & isolated & $\begin{array}{c}\text { Piers \#9 and \#11 \& CSBs } \\
\quad \# 9 \text { and \#11 }\end{array}$ & SLS, $100 \%$ & $15 / 11 / 2013$ \\
\hline p02 & isolated & $\begin{array}{c}\text { Piers \#9 and \#11 \& CSBs } \\
\# 9 \text { and \#11 }\end{array}$ & ULS, $70 \%$ & $15 / 11 / 2013$ \\
\hline q01 & isolated & Pier \#9 \& CSB \#9 & SLS, $100 \%$ & $18 / 11 / 2013$ \\
\hline q02 & isolated & Pier \#9 \& CSB \#9 & ULS, $65 \%$ & $18 / 11 / 2013$ \\
\hline q03 & isolated & Pier \#9 \& CSB \#9 & ULS, $65 \%$ & $18 / 11 / 2013$ \\
\hline k09 & as built & Piers \#9 and \#11 & ULS, $100 \%$ & $19 / 11 / 2013$ \\
\hline \multicolumn{5}{|c|}{ Updating of the OpenSEES RM and NSs } \\
\hline $\mathrm{k} 10$ & as built & Piers \#9 and \#11 & ULS, $100 \%$ & $21 / 11 / 2013$ \\
\hline \multicolumn{5}{|c|}{ Updating of the OpenSEES RM and NSs } \\
\hline $\mathrm{k} 12$ & as built & Piers \#9 and \#11 & ULS, $200 \%$ & $21 / 11 / 2013$ \\
\hline \multicolumn{5}{|c|}{ Updating of the OpenSEES RM and NSs } \\
\hline r01 & Isolated & CSB \#9 & ULS, $65 \%$ & $20 / 11 / 2013$ \\
\hline $\mathrm{rO2}$ & Isolated & CSB \#9 & ULS, $80 \%$ & $20 / 11 / 2013$ \\
\hline r03 & Isolated & CSB \#9 & ULS, $90 \%$ & $20 / 11 / 2013$ \\
\hline
\end{tabular}

Each test lasted $4000 \mathrm{sec}$, except Test k07, stopped at $1320 \mathrm{sec}$ after unexpected excess displacement of piers. Since preliminary characterization of CSB isolation devices conducted in Subsection 4.3 highlighted variable values of friction coefficient $\mu_{f}$, then in HS 101 and 102 numerical CSBs were coupled to PS portal piers. Conversely, HS tests of the isolated viaduct, namely Tests n01, p01, p02, q01, q02, q03, r01, r02 and r03 were executed with at least one physical group of isolators and reduced values of vertical forces N. Thus, PS piers were preserved from excess transverse forces caused by higher $\mu_{f}$ values. Moreover, the ULS accelerogram was applied with reduced PGA values. Once verified the effectiveness of the proposed seismic retrofitting scheme, ULS testing on the as built configuration were conducted through HS Tests k09 and k10. To simulate an aftershock event on the damaged bridge, k10 replicated k09. Moreover, to estimate the behavior of the viaduct when subject to a seismic event beyond design conditions, the ULS accelerogram was applied with a $200 \%$ magnified PGA value during Test k12. Later and less significant Tests $\mathrm{r} 01$, r02 and $\mathrm{r} 03$ considered physical CSBs of Pier \#9. All specimens carried full gravity forces and the ULS accelerogram was applied with reduced PGAs. 
As highlighted in $[7,8]$, the portal piers accumulated damage during each seismic event, while the deck remained in the linear regime. To track the progressive degradation of PSs portal piers, both the maximum concrete strength $f_{p c}$ and the relevant unloading/reloading stiffness $2 \mathrm{f}_{\mathrm{pc}} / \varepsilon_{\mathrm{psc} 0}$ of the OpenSEES RM of Subsection 3.1 were updated offline according to the test program of Table 3 . The updating was based on the minimization of the root mean square error of experimental and numerical restoring forces of Piers \#9 and \#11. In a greater detail, the second block of Figure 16 refers to the FE model updating based on experimental data of single Piers \#9 and \#11 assembled in OpenSEES. Conversely, the third block defines the transfer of updated mechanical properties of Piers \#9 and \#11 to the remaining hollow and solid piers of the OpenSEES RM defined in Subsection 3.1. Successively, the fourth step conducted with the OpenSEES RM will take into account any possible non-linearity both in the modeled Piers \#9 and \#11 and in the remaining piers of the NS caused by the seismic input to be employed in HS. Then, run by run, nonlinear parameters of reduced NSs were tuned to replicate the predicted response of the latest OpenSEES RM in the fourth block. As a result, the testing campaign accounted for a consistent degradation of both NSs and PSs portal piers. It must be noticed that the strict scheduling of Table 3 allowed for very short breaks between tests. Accordingly, time windows of a few hours confined all numerical tasks linked to the updating of the OpenSEES RM and the subsequent tuning of reduced NSs. The flowchart reported in Figure 16 summarizes the applied model update test procedure.

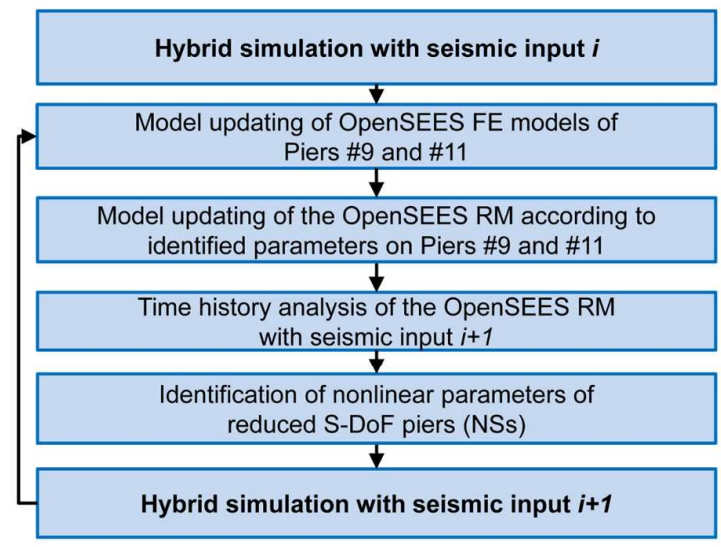

Figure 16. The offline model updating testing procedure.

A more detailed description of the applied procedure based on the OpenSEES RM can be found in $[21,32]$.

\section{HYBRID SIMULATION RESULTS}

Experimental results of HS in both the as built and isolated configurations are discussed below. In addition to global quantities such as lateral top displacements of portal piers, base shear, curvature estimates, shear deformation and slippage of rebars provided deep insight into the local cross sectional response of both PS piers. For clarity, all results reported in this section refer to the reduced scale model of the viaduct.

\subsection{As built configuration}

The first significant HS focused on the linear response of the bridge. To this end, the SLS accelerogram scaled to $10 \%$ of its PGA value was applied through Test k06 of Table 3. According to preliminary numerical simulation, physical piers were not damaged. Conversely, Test k07 aimed to induce a realistic damage pattern in PS piers through the HS of the viaduct response at the SLS. Nevertheless, displacement 
responses exceeded numerical predictions and the test was stopped after 6.6s only. Limited hairline cracks were observed on transverse beams of Piers \#9 and \#11. The resulting pattern can be clearly seen in Figure 17, which shows the axial strain field of the transverse beam of Pier \#11, see Figure 12(b), obtained from stereophotogrammetry acquisitions.

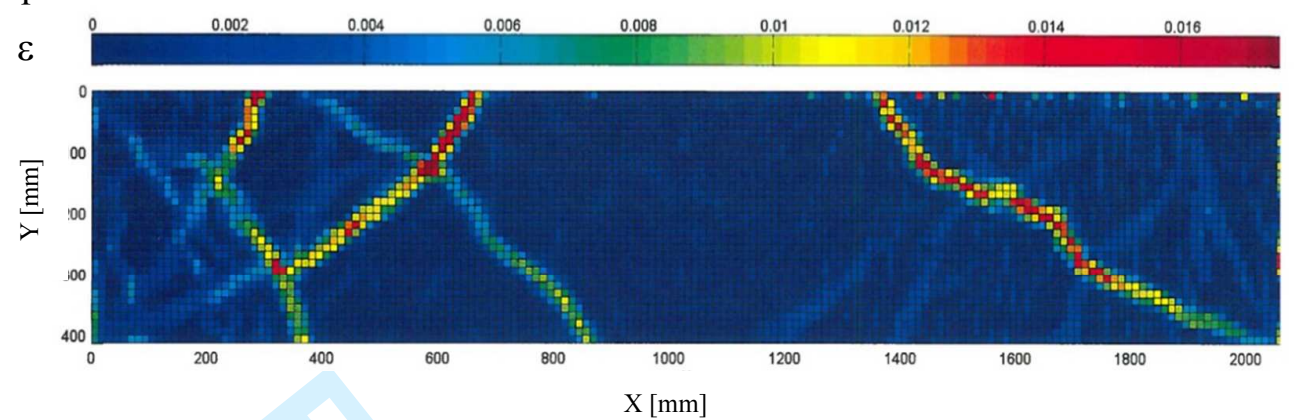

Figure 17. Contour plot of the surface axial strain field of the transverse beam of Pier \#11 at the end of HS k07.

A flexural-shear damage mechanism triggered cracking, which propagated from end sections to the middle of the transverse beam. In fact, assuming a bending moment with linear variation and a constant shear force along the element length, end sections were characterized by higher deviatoric stresses. Limited cracks owing to bond-slip effects were observed at column bases; relevant LVDT sensors recorded a peak uplift displacement of $0.2 \mathrm{~mm}$. Relevant data were evaluated and Figure 18 reports time histories of both shear deformation of the lower transverse beam and curvature of the bottom cross section of a column of Pier \#11.

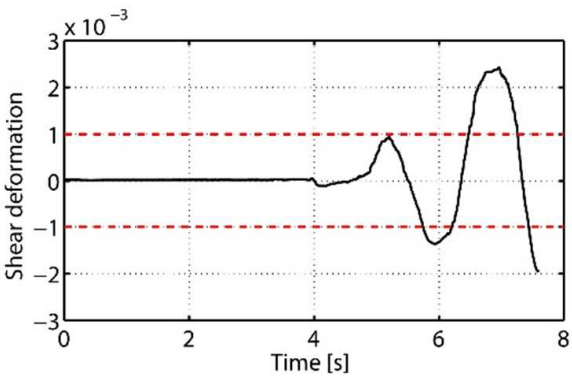

a

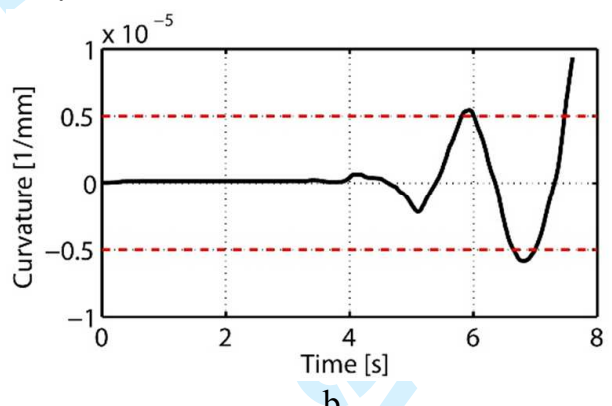

b

Figure 18. Time histories of: a) shear deformation of the transverse beam; and b) curvature of the column base cross section of Pier \#11 during HS k07. Dashed red lines highlight linear threshold values.

The resulting peaks of both curvature and shear deformation noticeably exceeded linear thresholds values. Moreover, Pier \#11 experienced a maximum drift ratio of about $0.6 \%$. As listed in Table 3, the HS k09 was designed to simulate the dynamic response of the as built bridge at ULS. As can be appreciated from Figure 19, significant shear cracks were observed on transverse beams and minor cracks opened at column bases. 


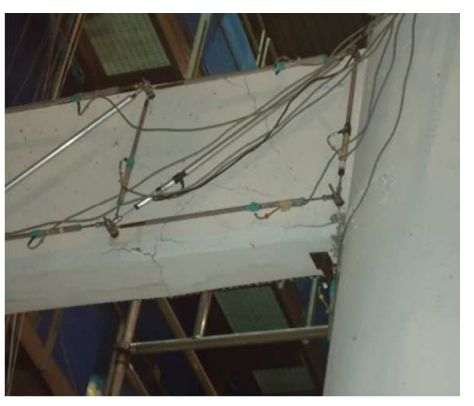

a

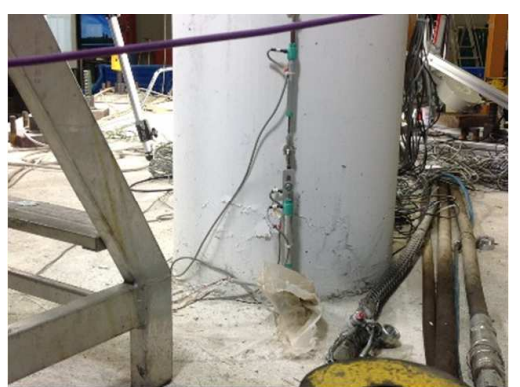

B

Figure 19. Close-up views of Pier \#11: a) transverse beam; and b) left column, after HS k09.

Conversely, global quantities - force-lateral deflection loops - measured on both piers during SLS and ULS HS relevant to Test k07 and Test k09 are shown in Figure 20. A markedly nonlinear behavior can be observed on both specimens at the ULS. Moreover, piers appear quite flexible with no softening even at high displacement levels. A pronounced pinch phenomenon is also evident. This was mainly caused by shear damage in transverse beams and large cracks at column bases with consequent fixedend rotation effects [37].

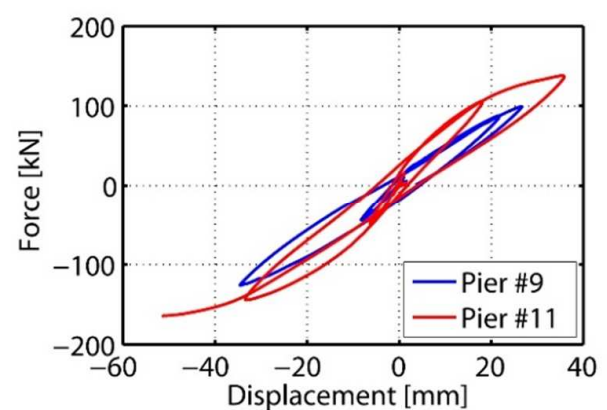

$\mathrm{b}$

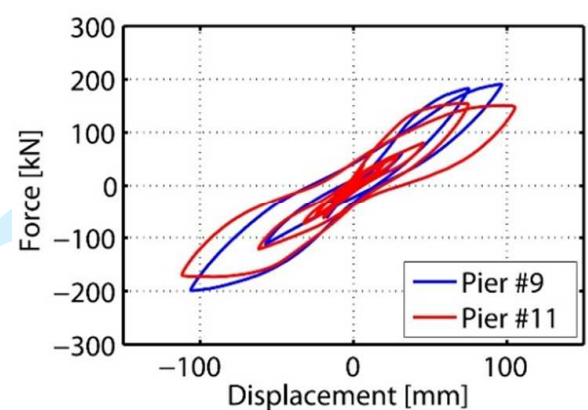

b

Figure 20. Force-deflection histories of Piers \#9 and \#11 for: a) HS k07; b) HS k09.

To simulate an aftershock event, the seismic input of Test k09 was repeated during HS k10. Figure 21 compares hysteretic loops of Pier \#9 and \#11 obtained from HS k09 and $\mathrm{k} 10$, respectively.

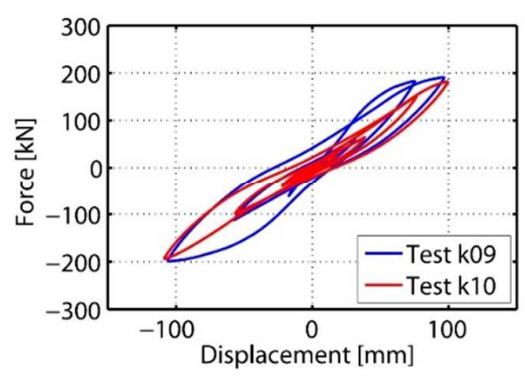

a

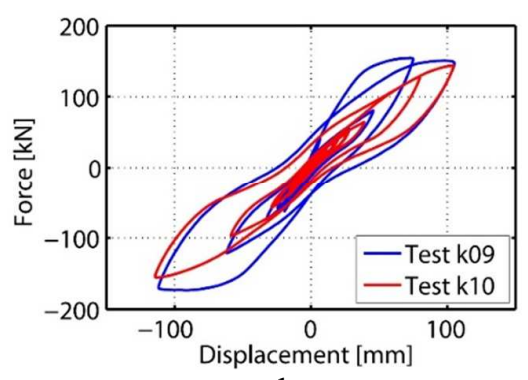

b

Figure 21. Comparison of hysteretic loops relevant to HS k09 and k10 of transversal restoring forces of: a) Pier \#9; and b) Pier \#11.

As can be seen in Figure 21, increasing column fixed-end rotation, due to higher slippage of rebars, shrank the hysteretic loops of piers at the second shock. Increased shear cracking on transverse beams further amplified this effect. 
In order to simulate a seismic event beyond design conditions, the same ULS accelerogram was applied with a PGA of $200 \%$ of its original value, i.e. HS k12 of Table 3. Figure 22 shows the relevant hysteretic loops for both PS piers. Restoring forces remained below ULS threshold values of HS k09, whereas both specimens experienced maximum displacement peaks twice as high. In greater detail, a $2.4 \% \mathrm{drift}$ ratio was observed on the short Pier \#11 where shear failure of the transverse beam occurred. Conversely, a smaller drift amount of $1.2 \%$ was measured on Pier \#9, which remained far from ultimate condition.

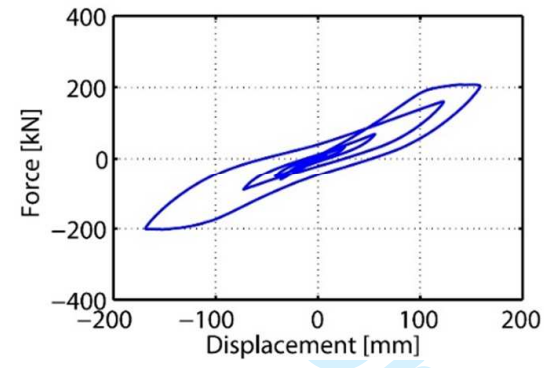

a

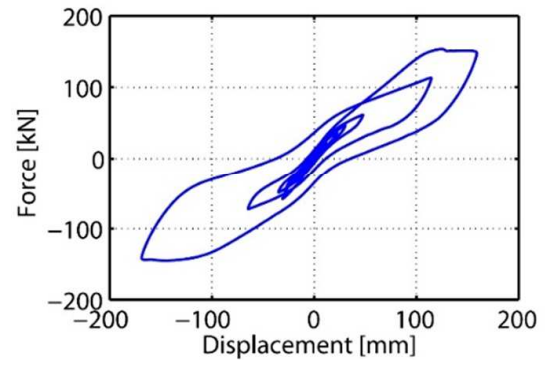

b

Figure 22. Force-deflection histories of HS k12 for: a) Piers \#9; b) Pier \#11.

To appreciate the behavior of Pier \#11, Figure 23(a) depicts large shear cracks associated with rebar buckling in transverse beams. Crack opening underneath the cap beam is evident in Figure 23(b).

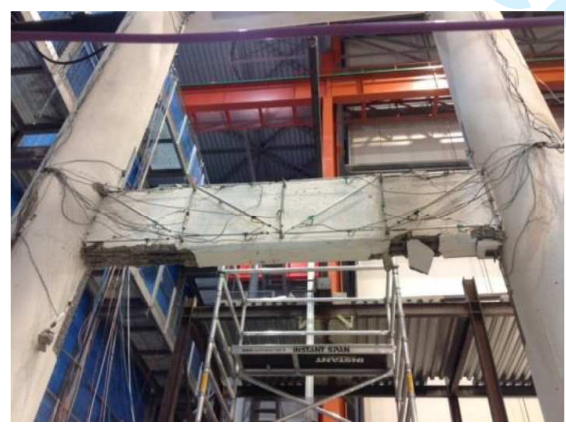

A

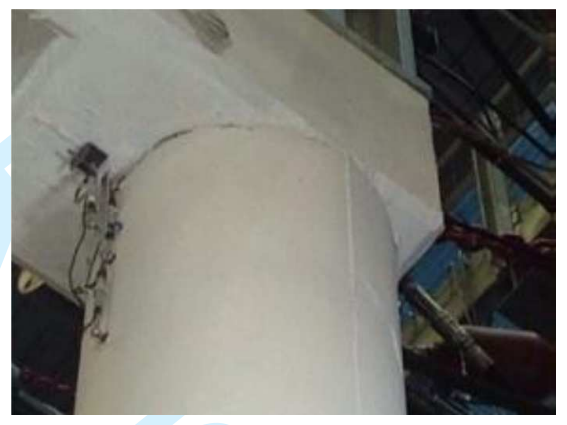

$b$

Figure 23. Damage state of Pier \#11 after HS k12: a) transverse beam damage; b) crack opening underneath the cap beam.

\subsection{Isolated configuration}

In agreement with Table 3, several HS tests were carried out on the isolated viaduct. In detail, HS 101 and 102 proved the effectiveness of the proposed seismic retrofit at SLS and ULS, respectively. In fact, Figure 24 compares hysteretic loops measured on both piers at ULS to the corresponding simulation k09 of the as built configuration. As devised, in portal piers CSB devices avoided hysteretic dissipation at ULS.

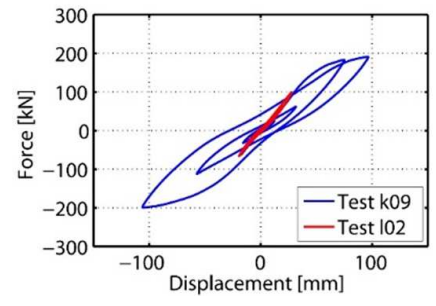

a

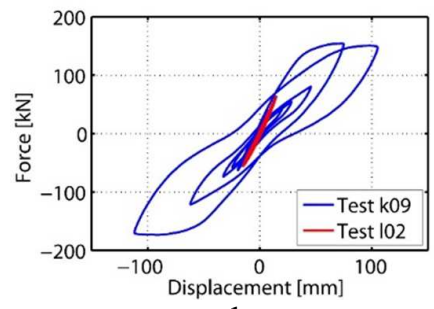

b

Figure 24. Comparison of hysteretic loops of HS k09 and 102 for: a) Pier \#9 and b) Pier \#11. 
Further HS testing was conducted considering CSBs in the physical substructures. In order to reproduce the design value of $\mathrm{V}$ in Eq (1) corresponding to $\mu_{f}=4 \%$, reduced $\mathrm{N}$ values were applied to physical isolators during $\mathrm{p}$ and $\mathrm{q}$ test series. With regard to SLS, pier responses complied with results obtained from Test 101, which was conducted with numerical isolators only. Despite reduced PGAs, piers experienced slight nonlinear responses during ULS HS. In this respect, Figure 25 gathers force-deflection loops obtained during Tests p01 and p02.

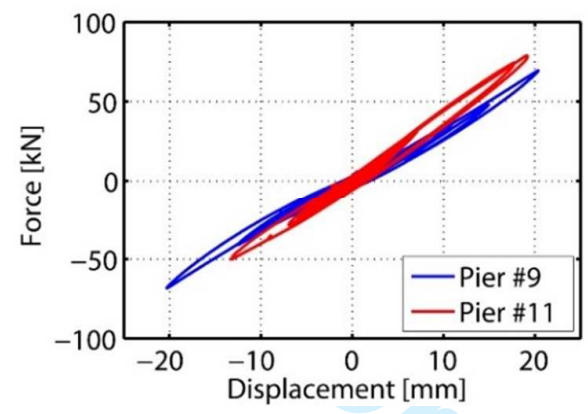

a

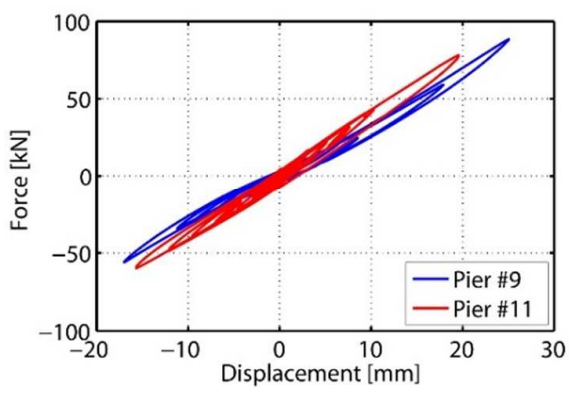

b

Figure 25. Force-Deflection cycles of Pier \#9 and Pier \#11: a) HS p01; b) HS p02.

A more pronounced nonlinear response was observed on pure NS piers during HS r01 and $\mathrm{r} 03$, see Table 3, which allowed for full vertical loads on physical CSB isolators. For such tests, $\mu_{f}$ was estimated to be $7 \%$ in Subsection 4.3 , significantly higher than the design value of $4 \%$. Plots of Figure 26 depict relevant force-deflection loops of both piers.

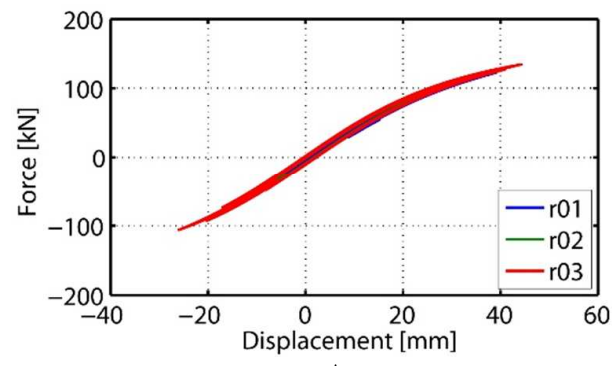

A

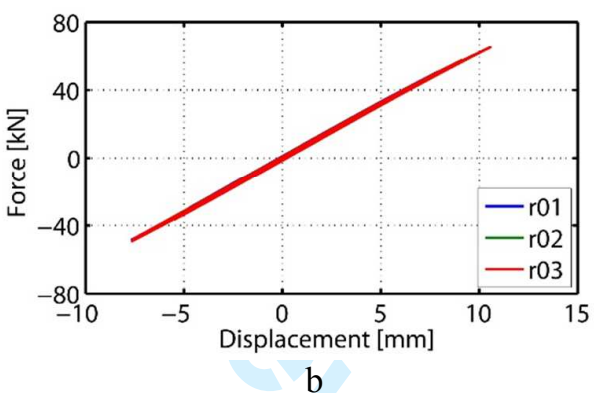

b

Figure 26. Force-deflection cycles of HS r01-r03: a) Piers \#9; b) Pier \#11.

As expected, the slender Pier \#9 experienced nonlinearities already at $65 \%$ of the PGA value, i.e. in the HS r01. Conversely, Pier \#11 always remained in the linear regime.

\section{CONCLUSIONS}

The Retro Transnational Access Project was funded by the European Commission within SERIES. The project dealt with the assessment of seismic vulnerability of an old $\mathrm{RC}$ viaduct with portal frame piers and investigated in depth the effectiveness of single concave sliding bearing devices through hybrid simulations on a large scale model. The research activity focused on experimental and numerical investigation of old bridges, designed chiefly for gravity loads. In particular, we assessed the seismic vulnerability of the Rio Torto Viaduct, an existing Italian structure with portal frame piers, and designed an isolation system based on sliding bearings.

A comprehensive experimental test campaign was performed at the ELSA Laboratory of JRC (Ispra, Italy). Two 1:2.5 scale specimens of single-bay RC frames with 2 levels 
(total height, $7.0 \mathrm{~m}$ ) and 3 levels (total height, $11.5 \mathrm{~m}$ ), were built and tested using hybrid simulation. In detail, two configurations of the sample viaduct were considered: 1) the as built viaduct subjected to several earthquake levels; 2) the isolated retrofitted viaduct fitted with sliding bearings. Natural records, based on a specific hazard analysis, were selected as earthquake input for hybrid simulation.

The comprehensive simulation campaign demonstrated the high structural vulnerability of the as built viaduct, justifying an appropriate seismic retrofit intervention. In this respect, we used single concave sliding bearing devices. Extensive damage patterns were detected, especially in the full solid short physical pier, where the transverse beam was subjected to severe cracking damage owing to shear. Additionally, significant fixed-end rotation occurred at pier column bases. This rotation was caused by high bond slip effects typically associated with plain steel rebars.

Moreover, the damage level of test results, as a function of earthquake levels, showed the reliability of the underlying OpenSEES-based models developed for the RETRO project. In addition, because $\mu_{f}$ value trends were identified, the potential of welldesigned single concave sliding bearing was fully exploited via hybrid simulation for real protection of viaduct piers. Finally, model reduction and updating was successfully used for numerical pier/device modeling. Overall, it was shown that with the numerical/control procedures for hybrid simulation developed by ELSA, it was possible to control up to eighteen actuator channels in the isolated case.

\section{ACKNOWLEDGMENTS}

The financial support from SERIES (Seismic Engineering Research Infrastructure for European Synergies) Project, funded within the $7^{\text {th }}$ Framework Programme of the European Commission [FP7/2007-2013] under grant agreement $\mathrm{n}^{\circ} 227887$, is greatly appreciated. Any opinions, findings and conclusions or recommendations expressed in this paper are those of the authors and do not necessarily reflect those of SERIES sponsors. The provision of isolator devices by ALGA is acknowledged as well.

\section{REFERENCES}

1- Pinto P.E., Mancini G., Seismic assessment and retrofit of existing bridges, The state of Earthquake Engineering Research in Italy: ReLUIS-DPC 2005-2008, 111-140, 2009, Doppiavoce, Napoli, Italy.

2- FHWA. Seismic Retrofitting Manual for Highway Bridges, Publ. FHWA-RD-94 052, 1995.

3- FHWA-MCEER. Seismic retrofitting manual for Highway Structures. Part 1- Bridges, 2006

4- CEN 2005. Eurocode 8: Design of structures for earthquake resistance - Part 3: Assessment and retrofitting of buildings, 2005.

5- Kappos, A.J., Saiidi, M.S., Aydınoğlu, M.N., Isaković, T. (Eds.) (2012). Seismic Design and Assessment of Bridges - Inelastic Methods of Analysis and Case Studies. Series: Geotechnical, Geological and Earthquake Engineering, Vol. 21, Springer.

6- Fernandes C., Melo J., Varum H., Costa A., Cyclic behaviour of a twospan RC beam built with plain reinforcing bars, Civil Engineering, 2011, 55/1, 21-29.

7- Paolacci, F. and Giannini, R., An experimental and numerical investigation on the cyclic response of a portal frame pier belonging to an old reinforced concrete viaduct. Earthquake Engineering and Structural Dynamics, 2012. 41: 1109-1127.

8- Alessandri S., Giannini, R. and Paolacci, F., Aftershock risk assessment and the decision to open traffic on bridges. Earthquake Engineering and Structural Dynamics, 2013, 42: 2255-2275.

9- Makris, N. and Chang, S., Effect of viscous, viscoplastic and friction damping on the response of seismic isolated structures, Earthquake Engineering and Structural Dynamics, 2000, 29, 1, pp. 85-107

10- Chang S., Makris N., Whittaker E. Thompson A, Experimental and analytical studies on the performance of hybrid isolation systems, Earthquake Engineering and Structural Dynamics, 2002, 31:421-443.

11- Magonette, G., Development and application of large-scale continuous pseudodynamic testing technique. Phil. Trans. R. Soc. Lond. A, 2001, 359:1771-1799 
12- Jung, R.Y., Shing, P.B. Performance evaluation of a real-time pseudodynamic test system, Earthquake Engineering \& Structural Dynamics, 2006, 35, 7,789-810.

13- Thewalt, R. and Mahin, S. A. Hybrid solution techniques for generalized pseudodynamic testing, 1987, Technical Report No. UCB/EERC-87/09, University of California Berkeley, CA, 1987.

14- Nakashima, M., Akazawa, T. and Sakaguchi, O. Integration method capable of controlling experimental error growth in substructure pseudo dynamic test. AIJ J. of Struct. Constr. Engng., 1993. 454:61-71

15- Pegon P. Continuous PsD Testing With Substructuring. In O. S. Bursi and D. J. Wagg, editors, Modern Testing Techniques for Structural Systems, Dynamics and Control. CISM-Springer Wien NewYork, 2008.

16- Jiang, Z., Kim, S.J., Plude, S. and Christenson, R., Real-time hybrid simulation of a complex bridge model with MR dampers using the convolution integral method, Smart Mater. Struct., 2013, 22.

17- Spencer, B.F., Chang, C-M, Frankie, T.M., Kuchma, D.A., Silva, P.F., Abdelnaby A.E., A phased approach to enable hybrid simulation of complex structures. Earthquake Engineering and Engineering Vibration, 2014, 13, 63-77.

18- Yang Y-S, Tsai, K.C., Elnashai, A.S. T., Hsieh T-J. An online optimization method for bridge dynamic hybrid simulations. Simulation Modelling Practice and Theory, 2012, 28:42- 54.

19- Kwon, O., Kammula, V. Model updating method for substructure pseudo-dynamic hybrid simulation. Earthquake Engineering \& Structural Dynamics, 2013, 42(13), 1971-1984.

20- Hashemi, M.J., Masroor, A., Mosqueda, G. Implementation of online model updating in hybrid simulation. Earthquake Engineering \& Structural Dynamics, 2014, 43:3, 395-412, 2014.

21- Paolacci, F. et al. 3-D Assessment of the seismic vulnerability of an old RC viaduct with frame piers

and study of the effectiveness of base isolation through PsD testing (RETRO), Eur Report $26471 \mathrm{EN}$, 2014. JRC., European Union.

22- Paolacci, F., Di Sarno, L., Pegon, P., Molina, J., Poljansek, M., Bursi, O. S. , Abbiati, G. Ceravolo, R. Erdik, M., Derisi, R., Mohamad, A., Assessment of the seismic behaviour of a retrofitted old R.C. highway bridge through PsD testing, SERIES Concluding Workshop - Joint with US-NEES, Earthquake Engineering Research Infrastructures, 2013. JRC-Ispra, I., May 28-30.

23- McKenna F, Fenves GL, Scott MH. OpenSees: open system for earthquake engineering simulation. PEER, 2007, University of California: Berkeley..

24- Della Corte, G., De Risi, R., Di Sarno, L., Approximate method for transverse response analysis of partially isolated bridges, Journal of Bridge Engineering, 2013, 18:11,1121-1130

25- Di Sarno, L.. Effects of multiple earthquakes on inelastic structural response. Engineering Structures, 2013, 56,5, 673-681.

26- NTC08 - Decreto Ministeriale 14.01.2008 - Norme tecniche per le costruzioni, 2008 (in Italian)

27- Marefat M.S., Masood S., Shirazi H., Rostamshirazi R., Khanmohammadi M., Cyclic Response of Concrete Beams Reinforced by Plain Bars, Journal of Earthquake Engineering, 2009, 13:463-481.

28- Bentz EC. "Sectional Analysis of Reinforced Concrete Members", PhD Thesis, Department of Civil Engineering, University of Toronto, 2000.

29- Klerk, D.D, Rixen, D.J. and Voormeeren, S.N. General Framework for Dynamic Substructuring: History, Review and Classification of Techniques. AIAA Journal, 2008, 5:46. 1169-1181.

30- Guyan, R.J. Reduction of stiffness and mass matrices. AIAA journal, 1965, 2:3, 380-380.

31- Bursi, O.S., Ceravolo, R., Erlicher, S., Zanotti Fragonara, L., Identification of the hysteretic behaviour of a partial-strength steel-concrete moment-resisting frame structure subject to pseudodynamic tests, 2012 Earthquake Engineering \& Structural Dynamics, 14:41, 1883-1903.

32- Abbiati G. Dynamic Substructuring of Complex Hybrid Systems Based on Time-Integration, Model Reduction and Model Identification Techniques", PhD Thesis, Department of Civil, Env. \& Mechanical Engineering, University of Trento, 2014.

33- Mostaghel, N. Analytical Description of Pinching, Degrading Hysteretic Systems. Journal of Engineering Mechanics, 1999, 2:125, 216-224.

34- Kumar, S., Itoh, Y., Saizuka, K., and Usami, T. Pseudodynamic Testing of Scaled Models. Journal of Structural Engineering, 1997, 123(4), 524-526.

35- Bonelli, A., Bursi, O.S., He, L., Magonette, G., Pegon, P., Convergence analysis of a parallel interfield method for heterogeneous simulations with substructuring, 2008, International Journal for Numerical Methods in Engineering, 75, 7, 800-825.

36- Lomiento G., Bonessio N., Benzoni G., Friction Model for Sliding Bearings under Seismic Excitation. Journal of Earthquake Engineering, 2013. 17.8, 1162-1191.

37- Arani K.K., Di Ludovico, M., Marefat, M.S., Prota, A. and Manfredi, G., Lateral Response Evaluation of Old Type Reinforced Concrete Columns with Smooth Bars. ACI Structural Journal, 2014, 111, 4, 827-838. 
25

26

27

29

30

31

33

34

35

36

37

38

39

40

41

42
43

44

45

46

47

48

49

51

52

53

54

55

56

57

59

60 

VIADUCT WITH PLAIN BARS AND SLIDING BEARINGS

\author{
Abbiati G. ${ }^{1}$, Bursi O.S. ${ }^{1}$, Caperan P. ${ }^{2}$, Di Sarno L. ${ }^{3}$, Molina F.J. ${ }^{2}$, Paolacci $F^{4}$, , Pegon P. ${ }^{2}$ \\ ${ }^{1}$ University of Trento, Department of Civil, Environmental and Mechanical Engineering, Via \\ Mesiano 77, 38123 Trento, Italy \\ ${ }^{2}$ European Commission, Joint Research Centre (JRC), Institute for the Protection and Security \\ of the Citizen, European Laboratory for Structural Assessment Unit, Via Enrico Fermi 2749, \\ 21027 Ispra (VA), Italy \\ ${ }^{3}$ University of Sannio, Department of Engineering, Piazza Roma 21, 82100 Benevento, Italy \\ ${ }^{4}$ University Roma Tre, Department of Engineering, Via Vito Volterra 62, 00146 Rome, Italy
}

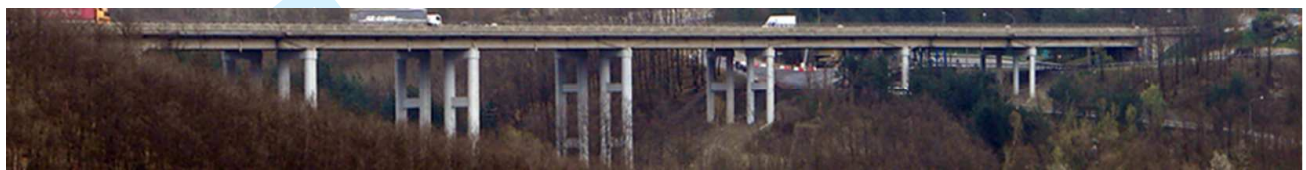

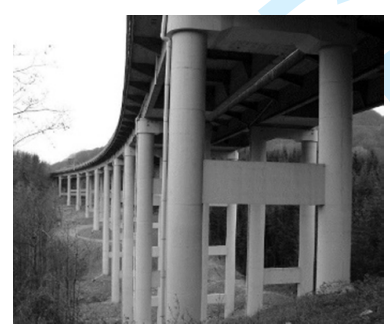

b

a)

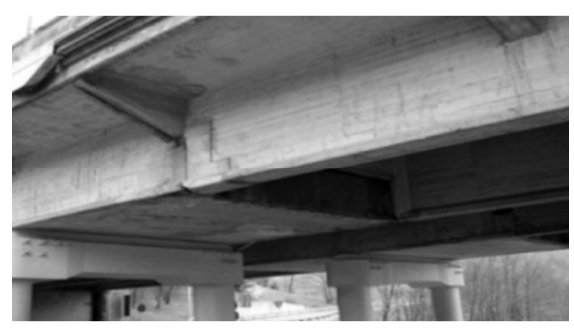

$\mathrm{C}$

Figure 1. a) Lateral view of the Rio Torto viaduct; b) detail of frame piers; and c) close-up view of a Gerber saddle.

Table 1. Heights of piers of the Rio Torto Bridge.

\begin{tabular}{cccccc}
\hline Pier & Height $[\mathbf{m}]$ & Pier & Height $[\mathbf{m}]$ & Pier & Height $[\mathbf{m}]$ \\
\hline 1 & 17.35 & 5 & 27.86 & 9 & 25.74 \\
\hline 2 & 30.61 & 6 & 39.41 & 10 & 17.19 \\
\hline 3 & 30.49 & 7 & 41.34 & 11 & 14.37 \\
\hline 4 & 26.75 & 8 & 36.49 & 12 & 13.80 \\
\hline
\end{tabular}

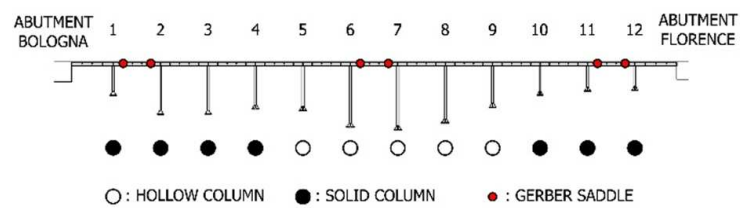

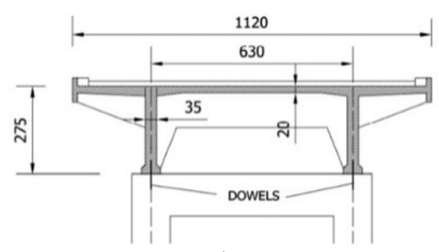

b

Figure 2. a) Structural scheme of the Rio Torto Bridge; b) Cross section of the deck. 


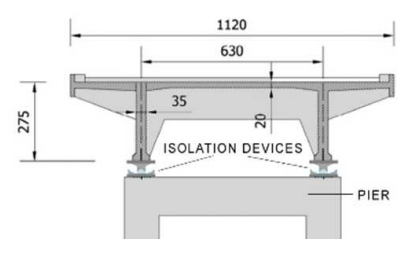

a

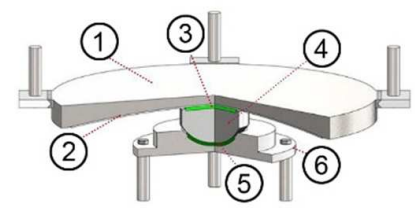

b

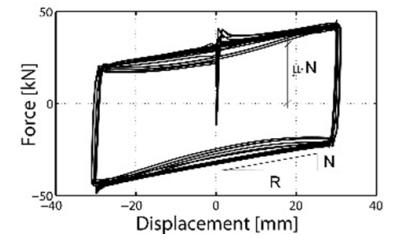

$\mathrm{c}$

Figure 3. a) Location of CSBs isolation devices on a generic frame pier; b) sketch of a single device; c) typical hysteretic loop in simple shear.
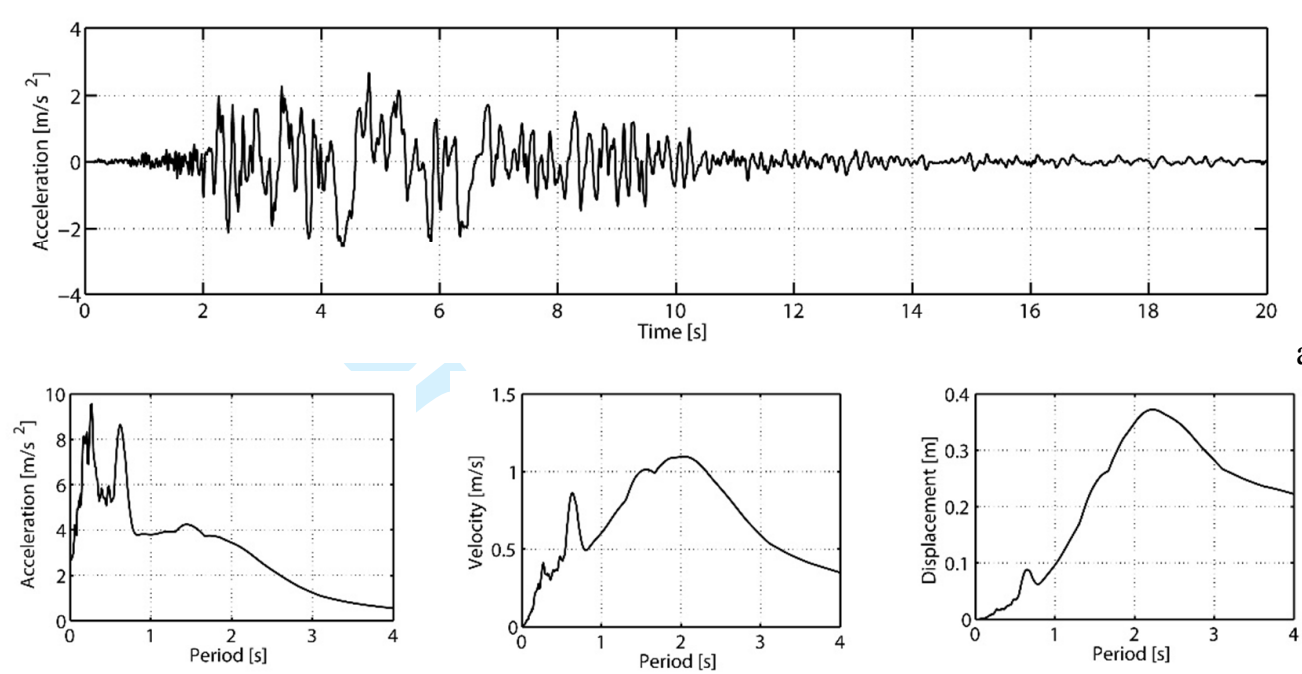

Figure 4. (a) Accelerogram used in numerical and hybrid simulation; (b) Response spectra of the Mirandola North-South component record of 29 May 2012: acceleration (left), velocity (middle) and displacement (right) spectrum.

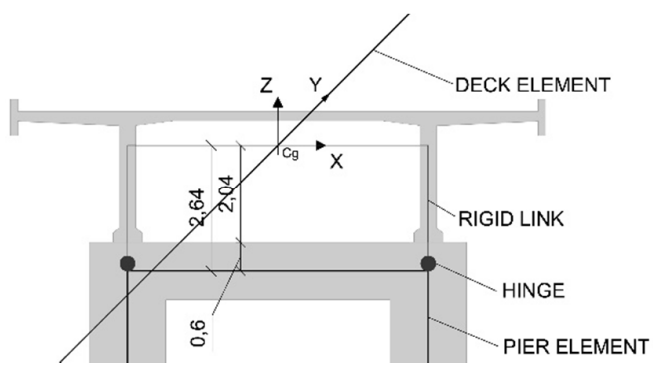

A

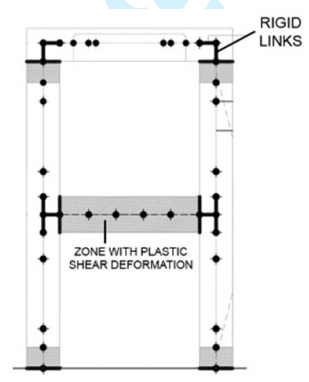

$b$

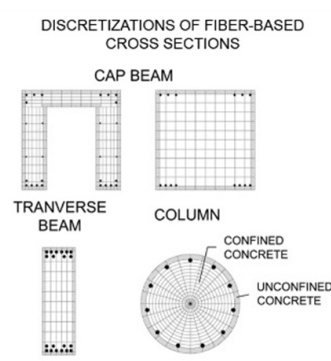

Figure 5 a) Details of the FE model of a pier-deck connection; b) schematic view of the OpenSEES fiber-based FE model of Pier \#12. Dimensions in meters.

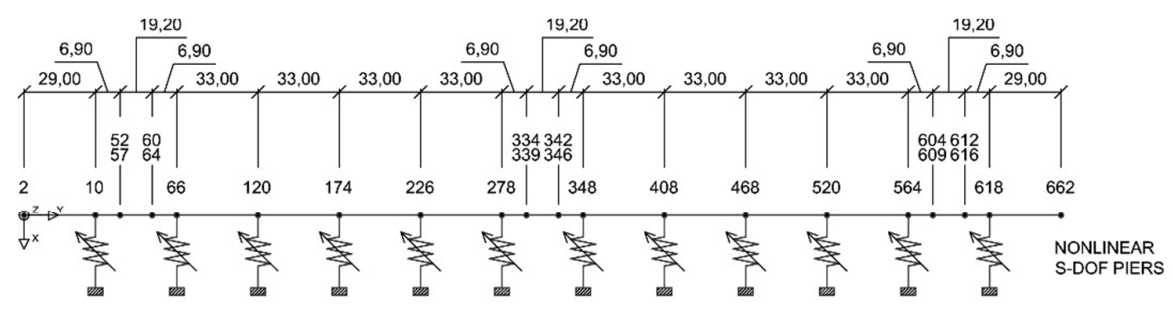




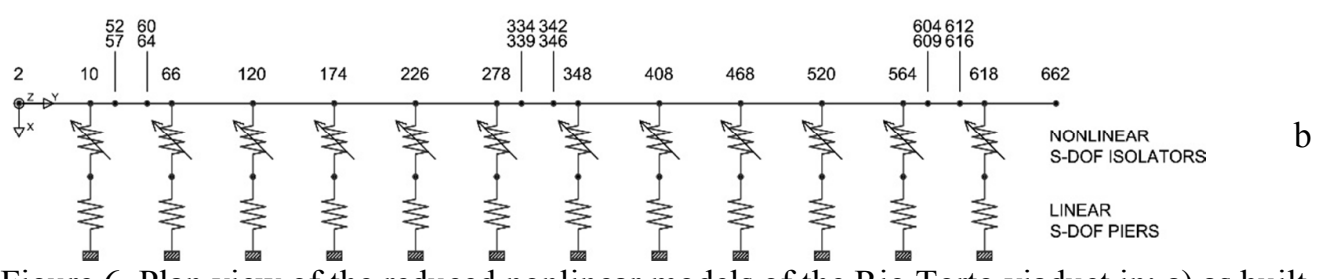

Figure 6. Plan view of the reduced nonlinear models of the Rio Torto viaduct in: a) as built configuration; b) isolated configuration. Dimensions in $\mathrm{m}$.

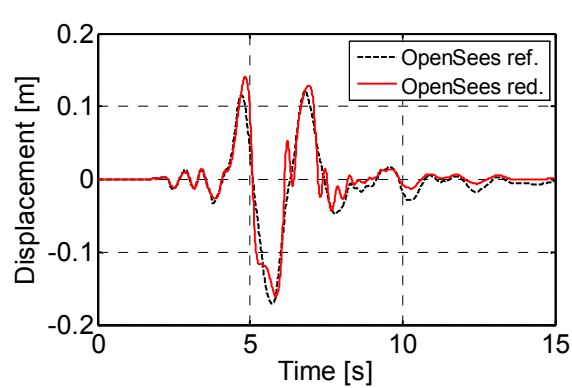

a

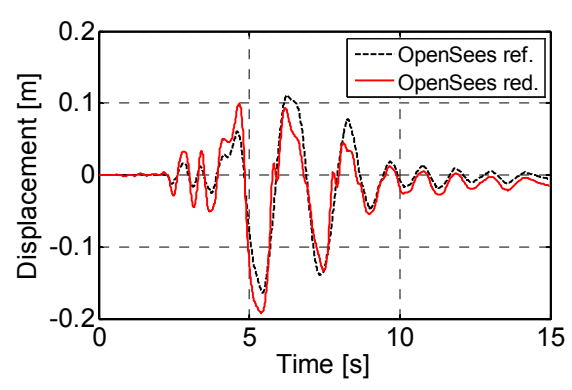

b

Figure 7. Comparisons of displacement responses of reference and reduced piers al ULS: a) Pier \#9; and b) Pier \#11.
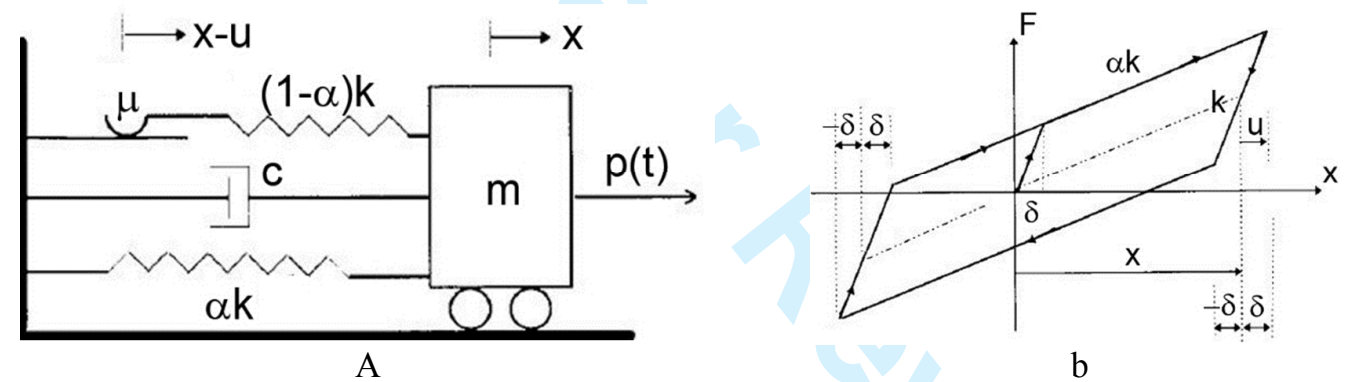

Figure 8. a) Hysteretic S-DoF oscillator; b) relevant bilinear hysteretic loop

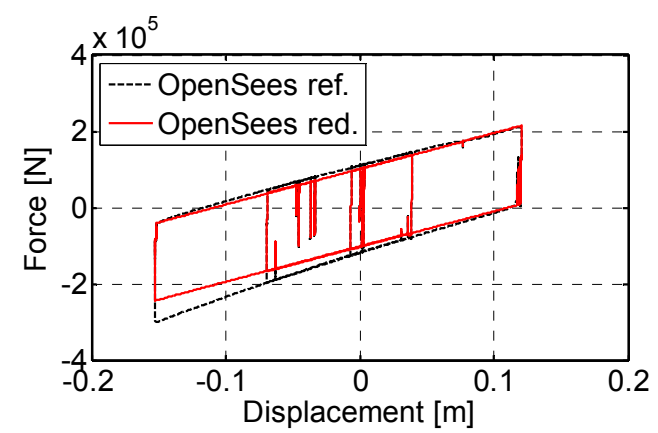

a

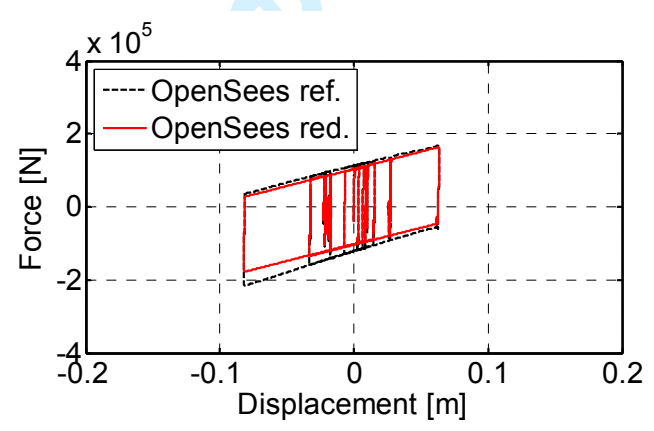

b

Figure 9. Comparisons of hysteretic loops of reference and reduced isolators at ULS installed on the pier right column of: a) Pier \#9; and b) Pier \#11. 


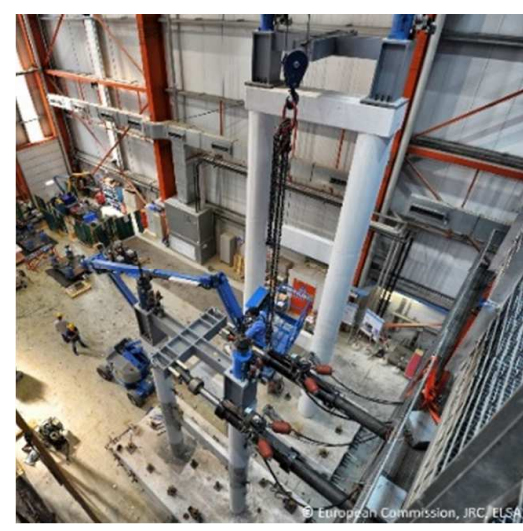

a

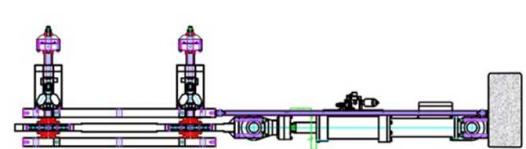

c)

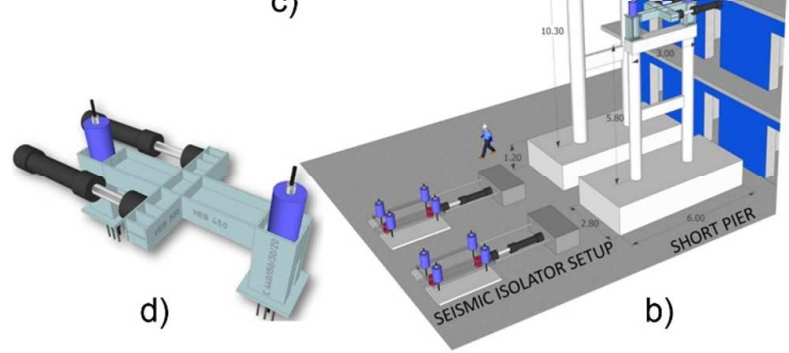

b, c, d

Figure 10. 1:2.5 mock-up scale specimens of Piers \#9 and \#11; b) view of the test set-up; c) CSBs set-up; d) horizontal and vertical loading system of frame piers.

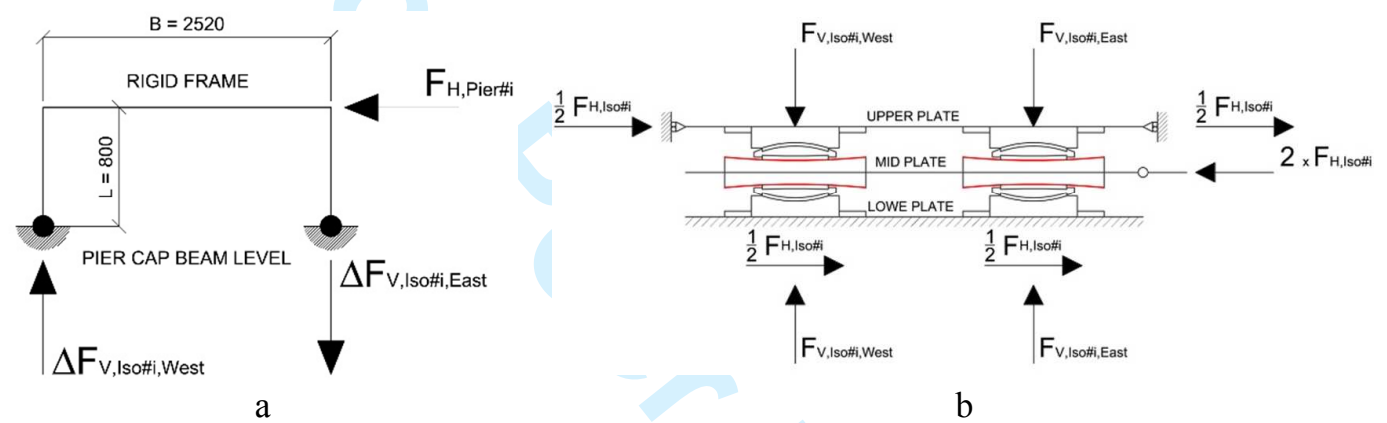

Figure 11. Structural schemes and relevant applied loads for: a) the rigid steel frame of each frame pier; b) the experimental set-up of a CSB isolator group.

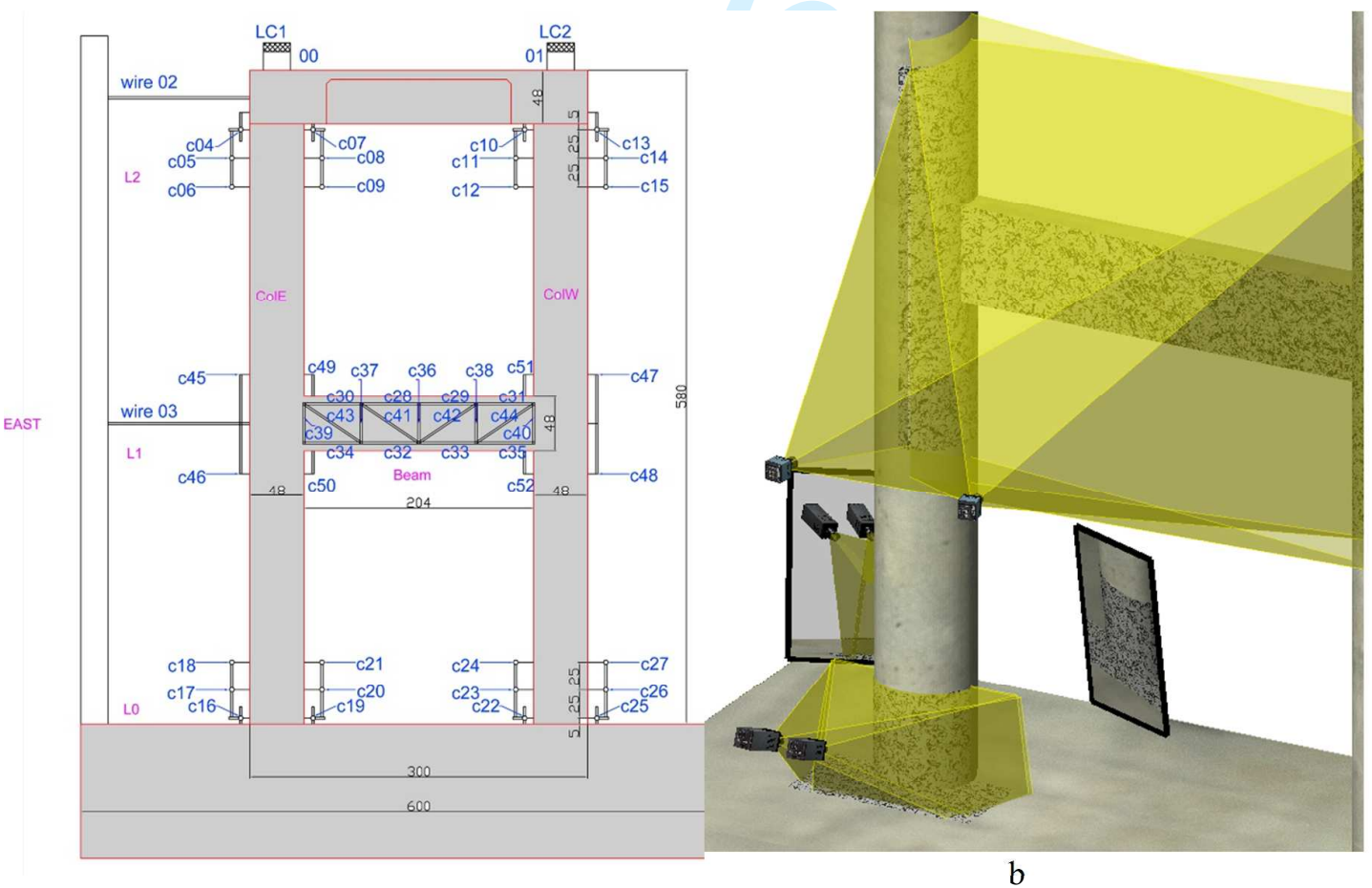


a

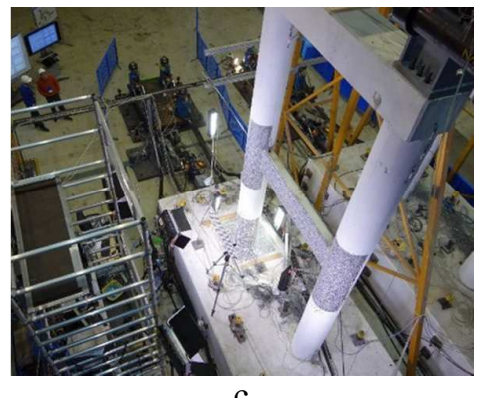

Figure 12. Measurement set-up for Pier \#11: a) layout of LVDT lattices; b) schematic view of the stereophotogrammetry acquisition system; c) photograph of the equipped pier.

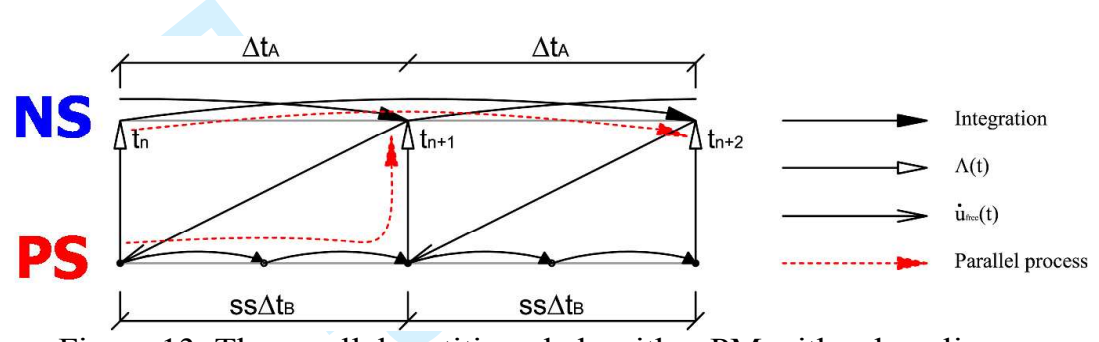

Figure 13. The parallel partitioned algorithm PM with subcycling.

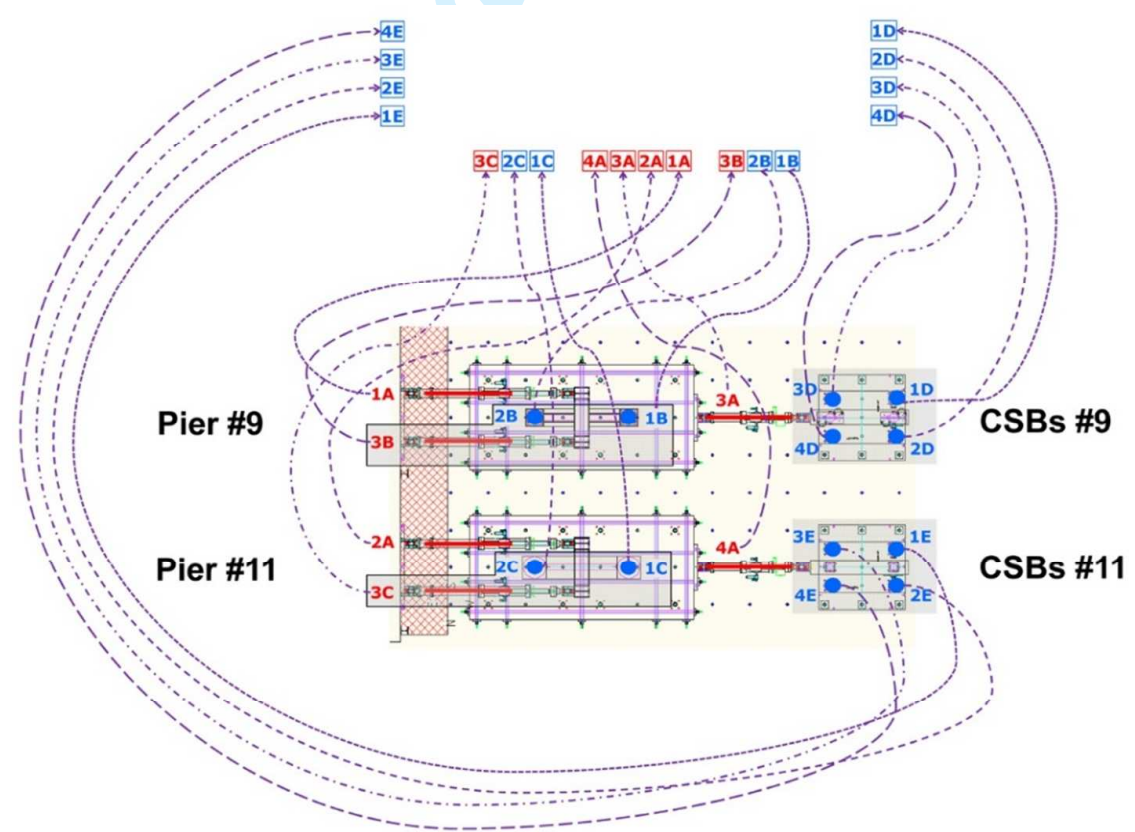

Figure 14. Plan view of the testing set-up with basic cable scheme for force and displacement pilot transducers.

Table 2 Characterization tests on scaled single CSB isolation devices

\begin{tabular}{cccc}
\hline Test \# & Specimen & $\begin{array}{c}\text { Amplitude range } \\
{[\mathbf{m m}]}\end{array}$ & $\begin{array}{c}\text { Peak velocity range } \\
{[\mathbf{m m} / \mathbf{s}]}\end{array}$ \\
\hline 1 & CSB \#9 & 30 (const.) & $0.63-37.7$ \\
\hline 2 & CSB \#9 & $50-10$ & $3.14-0.63$ \\
\hline 3 & CSB \#11 & $50-10$ & $3.14-0.63$ \\
\hline 4 & CSB \#11 & 30 (const.) & $0.63-37.7$ \\
\hline
\end{tabular}




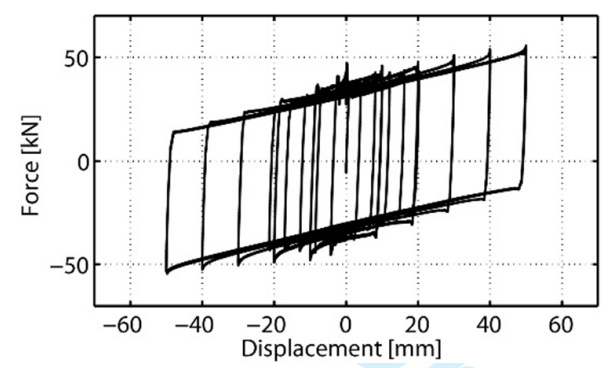

A

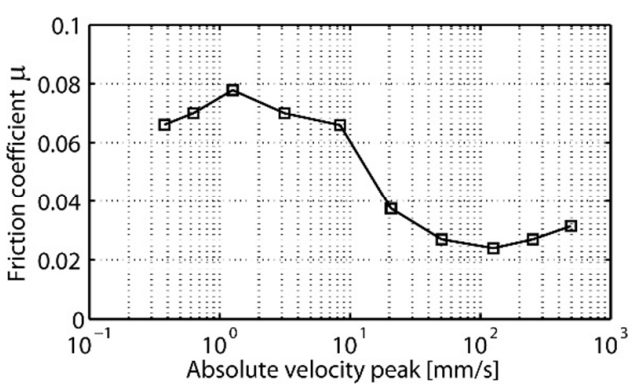

b

Figure 15. CSB characteristics of Pier \#11: a) hysteretic response; b) experimental values of $\mu_{f}$ vs velocity peaks at $\lambda=1$.

Table 3. Nomenclature and characteristics of HS.

\begin{tabular}{|c|c|c|c|c|}
\hline Label & Configuration & Physical Substructures & $\begin{array}{c}\text { Accelerogram and PGA } \\
\text { scaling }\end{array}$ & Date \\
\hline k06 & as built & Piers \#9 and \#11 & SLS, $10 \%$ & $08 / 11 / 2013$ \\
\hline \multicolumn{5}{|c|}{ Updating of the OpenSEES RM and NSs } \\
\hline $\mathrm{k} 07$ & as built & Piers \#9 and \#11 & SLS, $100 \%$ & $08 / 11 / 2013$ \\
\hline \multicolumn{5}{|c|}{ Updating of the OpenSEES RM and NSs } \\
\hline 101 & isolated & Piers \#9 and \#11 & SLS, $100 \%$ & $12 / 11 / 2013$ \\
\hline 102 & isolated & Piers \#9 and \#11 & ULS, $100 \%$ & $13 / 11 / 2013$ \\
\hline n01 & isolated & CSBs \#9 and \#11 & SLS, $100 \%$ & $14 / 11 / 2013$ \\
\hline p01 & isolated & $\begin{array}{c}\text { Piers \#9 and \#11 \& CSBs } \\
\# 9 \text { and \#11 }\end{array}$ & SLS, $100 \%$ & $15 / 11 / 2013$ \\
\hline p02 & isolated & $\begin{array}{c}\text { Piers \#9 and \#11 \& CSBs } \\
\# 9 \text { and \#11 } \\
\end{array}$ & ULS, $70 \%$ & $15 / 11 / 2013$ \\
\hline $\mathrm{q} 01$ & isolated & Pier \#9 \& CSB \#9 & SLS, $100 \%$ & $18 / 11 / 2013$ \\
\hline $\mathrm{q} 02$ & isolated & Pier \#9 \& CSB \#9 & ULS, $65 \%$ & $18 / 11 / 2013$ \\
\hline q03 & isolated & Pier \#9 \& CSB \#9 & ULS, $65 \%$ & $18 / 11 / 2013$ \\
\hline k09 & as built & Piers \#9 and \#11 & ULS, $100 \%$ & $19 / 11 / 2013$ \\
\hline \multicolumn{5}{|c|}{ Updating of the OpenSEES RM and NSs } \\
\hline k10 & as built & Piers \#9 and \#11 & ULS, $100 \%$ & $21 / 11 / 2013$ \\
\hline \multicolumn{5}{|c|}{ Updating of the OpenSEES RM and NSs } \\
\hline k12 & as built & Piers \#9 and \#11 & ULS, $200 \%$ & $21 / 11 / 2013$ \\
\hline \multicolumn{5}{|c|}{ Updating of the OpenSEES RM and NSs } \\
\hline r01 & Isolated & CSB \#9 & ULS, $65 \%$ & $20 / 11 / 2013$ \\
\hline $\mathrm{rO2}$ & Isolated & CSB \#9 & ULS, $80 \%$ & $20 / 11 / 2013$ \\
\hline r03 & Isolated & CSB \#9 & ULS, $90 \%$ & $20 / 11 / 2013$ \\
\hline
\end{tabular}



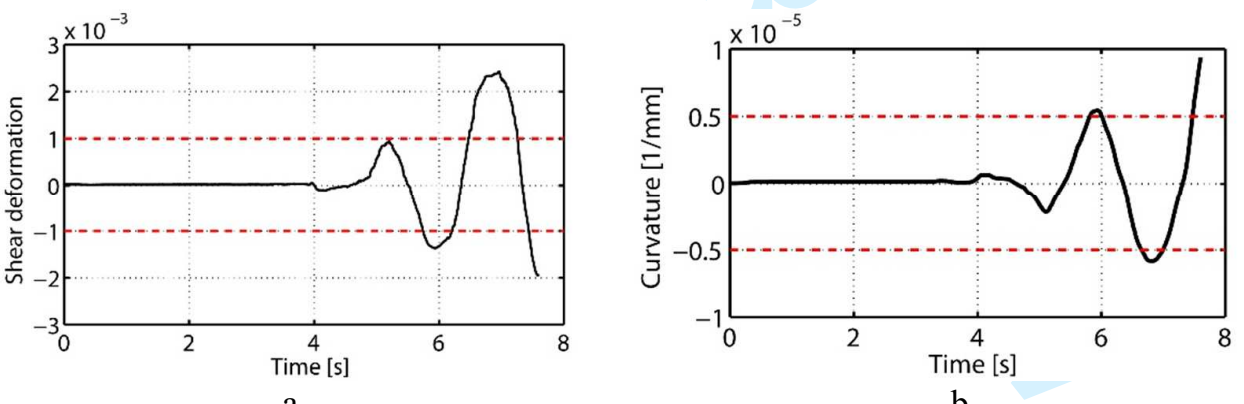

Figure 18. Time histories of: a) shear deformation of the transverse beam; and b) curvature of the column base cross section of Pier \#11 during HS k07. Dashed red lines highlight linear threshold values.

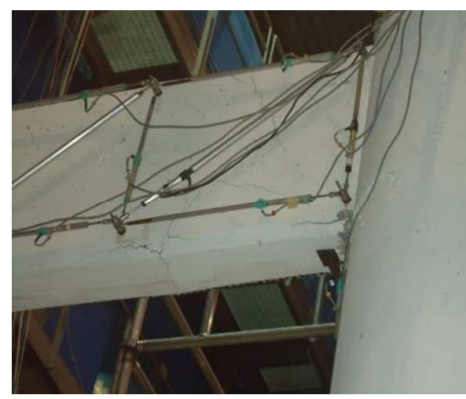

a

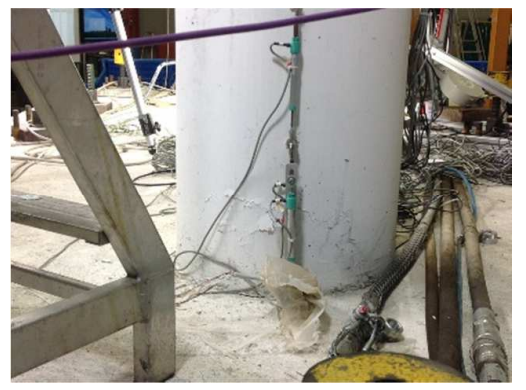

B 
Figure 19. Close-up views of Pier \#11: a) transverse beam; and b) left column, after HS k09.

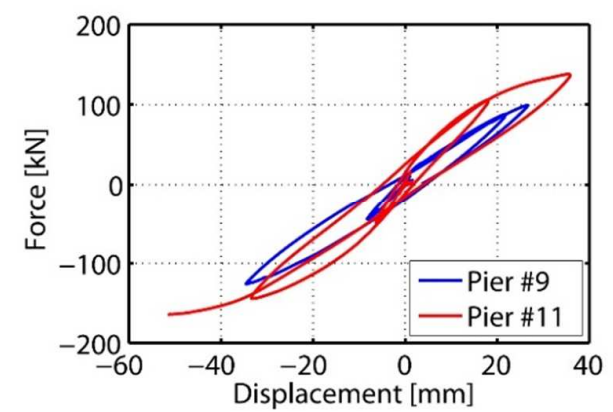

$\mathrm{b}$

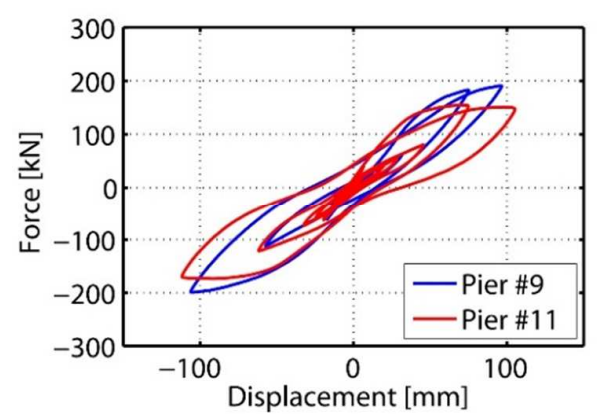

$\mathrm{b}$

Figure 20. Force-deflection histories of Piers \#9 and \#11 for: a) HS k07; b) HS k09.

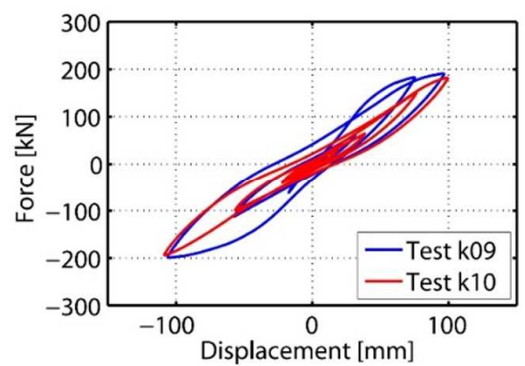

a

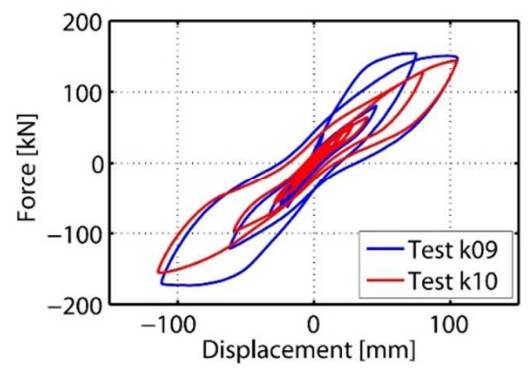

$\mathrm{b}$

Figure 21. Comparison of hysteretic loops relevant to HS k09 and k10 of transversal restoring forces of: a) Pier \#9; and b) Pier \#11.

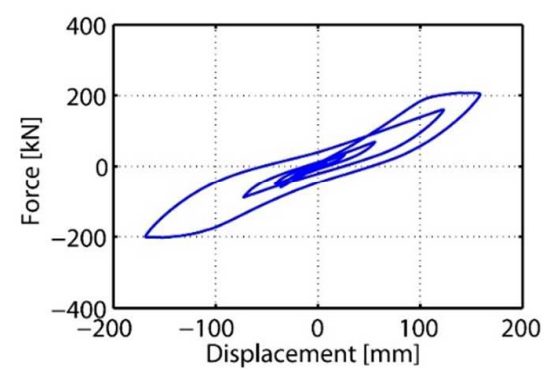

a

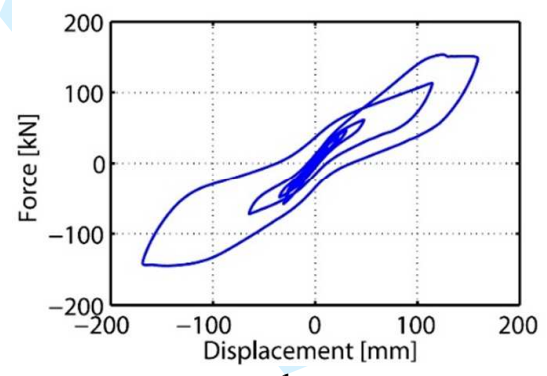

$\mathrm{b}$

Figure 22. Force-deflection histories of HS k12 for: a) Piers \#9; b) Pier \#11.

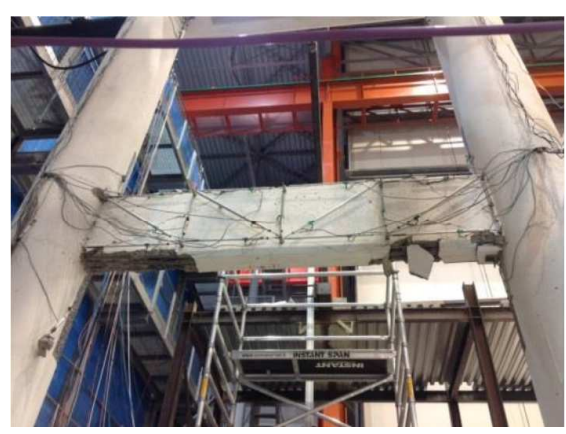

A

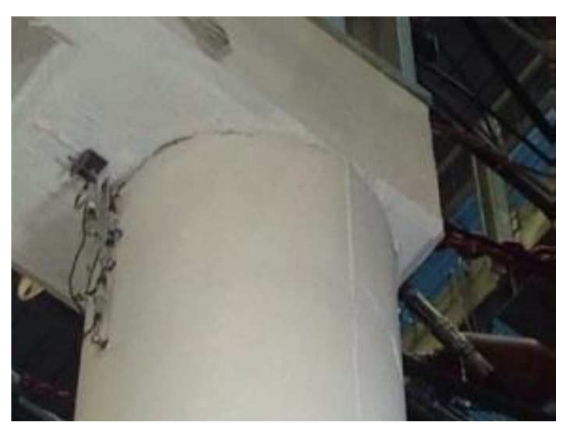

$\mathrm{b}$

Figure 23. Damage state of Pier \#11 after HS k12: a) transverse beam damage; b) crack opening underneath the cap beam. 


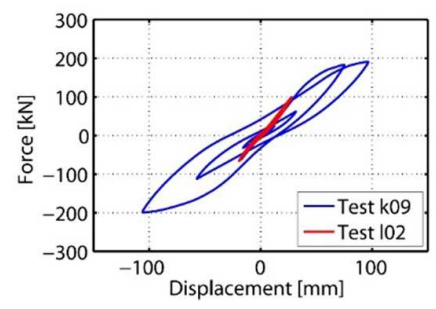

a

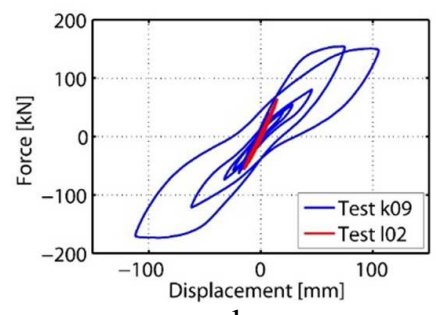

b

Figure 24. Comparison of hysteretic loops of HS k09 and 102 for: a) Pier \#9 and b) Pier \#11.
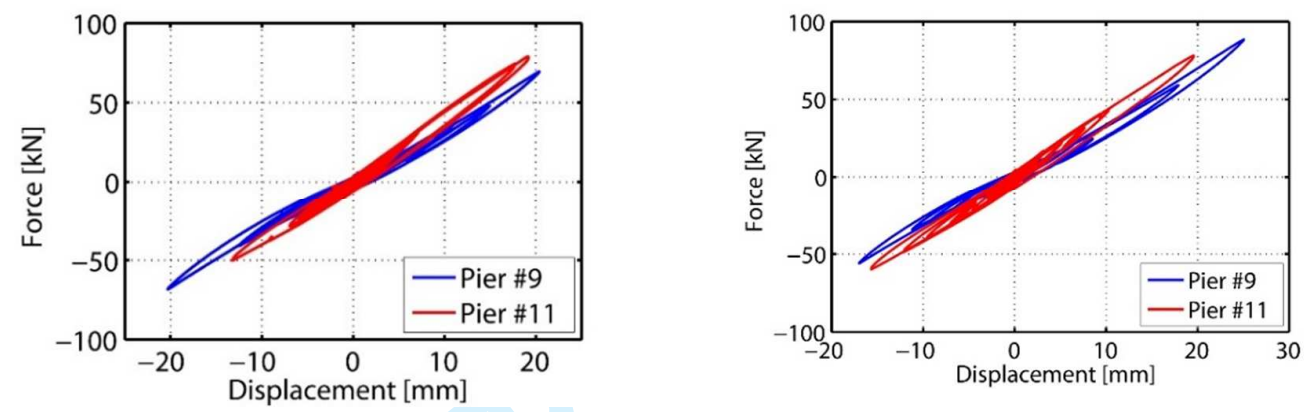

a

$\mathrm{b}$

Figure 25. Force-Deflection cycles of Pier \#9 and Pier \#11: a) HS p01; b) HS p02.

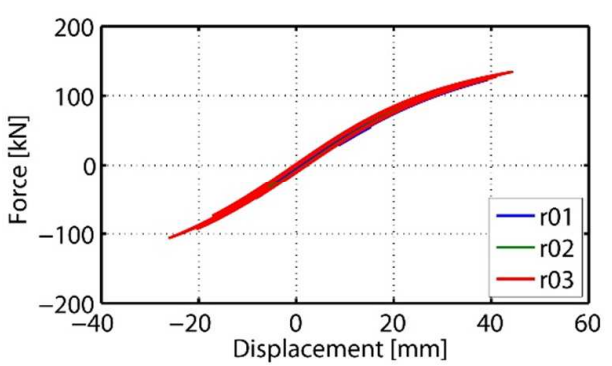

A

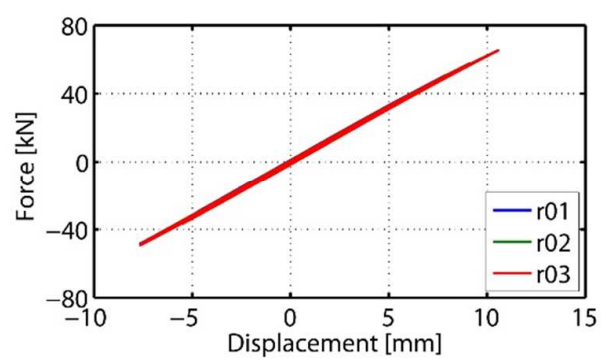

$\mathrm{b}$

Figure 26. Force-deflection cycles of HS r01-r03: a) Piers \#9; b) Pier \#11. 